\title{
Passive Clearing and 3D Lightsheet Imaging of the Intact and Injured Spinal Cord in Mice
}

\author{
Dylan A. McCreedy ${ }^{1,2,3,4 *}$, Frank L. Jalufka ${ }^{1}$, Madison E. Platt ${ }^{1}$, Sun Won Min ${ }^{1}$, \\ Megan A. Kirchhoff', Anna L. Pritchard ${ }^{3}$, Shelby K. Reid ${ }^{4}$, Ronald Manlapaz ${ }^{2}$, \\ Eszter Mihaly ${ }^{2}$, Jessica C. Butts ${ }^{2}$, Nisha R. Iyer ${ }^{5}$, Shelly E. Sakiyama-Elbert ${ }^{6}$, \\ Steven A. Crone ${ }^{7,8,9}$ and Todd C. McDevitt ${ }^{2,10 *}$
}

\begin{abstract}
${ }^{1}$ Department of Biology, Texas A\&M University, College Station, TX, United States, ${ }^{2}$ Gladstone Institutes, San Francisco, CA, United States, ${ }^{3}$ Department of Biomedical Engineering, Texas A\&M University, College Station, TX, United States, ${ }^{4}$ Texas A\&M Institute for Neuroscience, College Station, TX, United States, ${ }^{5}$ Wisconsin Institute for Discovery, University of Wisconsin-Madison, Madison, WI, United States, ${ }^{6}$ Department of Biomedical Engineering, University of Texas at Austin, Austin, TX, United States, ' Division of Neurosurgery, Cincinnati Children's Hospital Medical Center, Cincinnati, OH, United States, ${ }^{8}$ Division of Developmental Biology, Cincinnati Children's Hospital Medical Center, Cincinnati, OH, United States, ${ }^{9}$ Department of Neurosurgery, College of Medicine, University of Cincinnati, Cincinnati, OH, United States, ${ }^{10}$ Department of Bioengineering and Therapeutic Sciences, University of California, San Francisco, San Francisco, CA, United States
\end{abstract}

OPEN ACCESS

Edited by:

Marc J. Ruitenberg,

University of Queensland, Australia

Reviewed by:

Jan Kaslin,

Australian Regenerative Medicine Institute (ARMI), Australia

Hong Wa Lao,

The University of Queensland, Australia

Faith H. Brennan,

The Ohio State University,

United States

*Correspondence:

Dylan A. McCreedy

dmccreedy@bio.tamu.edu

Todd C. McDevitt

todd.mcdevitt@gladstone.ucsf.edu

Specialty section:

This article was submitted to Cellular Neuropathology, a section of the journal

Frontiers in Cellular Neuroscience

Received: 24 March 2021

Accepted: 07 July 2021

Published: 02 August 2021

Citation:

McCreedy DA, Jalufka FL, Platt ME, Min SW, Kirchhoff MA, Pritchard AL, Reid SK, Manlapaz R, Mihaly E, Butts JC, lyer NR, Sakiyama-Elbert SE, Crone SA and McDevitt TC (2021) Passive Clearing and 3D Lightsheet Imaging of the Intact and Injured Spinal Cord in Mice. Front. Cell. Neurosci. 15:684792. doi: 10.3389/fncel.2021.684792
The spinal cord contains a diverse array of sensory and motor circuits that are essential for normal function. Spinal cord injury (SCl) permanently disrupts neural circuits through initial mechanical damage, as well as a cascade of secondary injury events that further expand the spinal cord lesion, resulting in permanent paralysis. Tissue clearing and 3D imaging have recently emerged as promising techniques to improve our understanding of the complex neural circuitry of the spinal cord and the changes that result from damage due to $\mathrm{SCl}$. However, the application of this technology for studying the intact and injured spinal cord remains limited. Here, we optimized the passive CLARITY technique (PACT) to obtain gentle and efficient clearing of the murine spinal cord without the need for specialized equipment. We demonstrate that PACT clearing enables 3D imaging of multiple fluorescent labels in the spinal cord to assess molecularly defined neuronal populations, acute inflammation, long-term tissue damage, and cell transplantation. Collectively, these procedures provide a framework for expanding the utility of tissue clearing to enhance the study of spinal cord neural circuits, as well as cellular- and tissue-level changes that occur following SCl.

\section{Keywords: spinal cord injury, lightsheet imaging, PACT, tissue clearing, neural circuits}

\section{INTRODUCTION}

The spinal cord mediates a complex repertoire of sensory and motor functions through a sophisticated network of neural circuits. SCI disrupts the transmission of neural signals and triggers widespread cellular and molecular events that mediate a secondary wave of tissue damage. While many different therapeutic strategies have been developed to limit secondary injury or promote

Abbreviations: BBT, boric acid buffer with $0.1 \%$ Triton $^{\mathrm{TM}} \mathrm{X}-100$; ChAT, choline acetyl transferase; CNS, central nervous system; eGFP, enhanced green fluorescent protein; hiPSC, human induced pluripotent stem cell; IF, immunofluorescent; MCT, micro-centrifuge tube; MIP, maximum intensity projection; NDS, normal donkey serum; O/N, overnight; PACT, passive CLARITY technique; PB, phosphate buffer; PBS, phosphate buffered saline; RI, refractive index; RIMS, refractive index matching solution; RT, room temperature; SCI, spinal cord injury; SDS, sodium dodecyl sulfate; T9, ninth thoracic vertebra. 
repair of damaged neural circuits (Kwon et al., 2011a,b; Tetzlaff et al., 2011; Griffin and Bradke, 2020), limited efficacy in the clinical setting has been achieved to date. Greater anatomical characterization of the intact and injured spinal cord may provide critical insight that can improve future studies to promote recovery after SCI. One of the major limitations to studying the spinal cord neural circuits, as well as the secondary pathological mechanisms that exacerbate tissue damage after SCI, has been the traditional use of labor-intensive and error-prone histological sectioning (Steward et al., 2003; Erturk et al., 2011).

Tissue clearing has emerged as a promising approach to render the opaque tissues of the CNS optically transparent thereby enabling whole volumetric imaging of the entire tissue without the need for physical sectioning (Richardson and Lichtman, 2015; Ueda et al., 2020). Many different tissue clearing protocols have been developed to date including hydrophobic clearing techniques that rely on organic solvents (e.g., 3DISCO), as well as hydrophilic and hydrogel-based techniques that utilize aqueous-based reagents (e.g., CUBIC and CLARITY, respectively) (Erturk et al., 2012; Chung et al., 2013; Susaki and Ueda, 2016; Tainaka et al., 2018). Hydrophobic-based clearing techniques promote rapid and thorough clearing of CNS tissue, but can quench fluorescent protein signals and may impact endogenous epitopes needed for IF labeling (Renier et al., 2014; Ueda et al., 2020). Hydrogel-based techniques can help preserve biomolecules, but often require additional forces such as electrophoresis to improve the speed and quality of tissue clearing (Chung et al., 2013; Tomer et al., 2014; Kim et al., 2015). Passive hydrogel-based protocols, such as the PACT, eliminate the need for specialized clearing equipment through reduced hydrogel crosslinking, which improves the rate of clearing and IF labeling while still maintaining sample integrity and transgenic fluorescence (Yang et al., 2014; Treweek et al., 2015).

Advances in tissue clearing techniques have enabled greater detailed analysis of intact neural circuits in the mouse brain, however, corresponding studies of the spinal cord have been more limited. Recent studies have demonstrated successful clearing of the murine spinal cord using hydrophobic clearing techniques, which has enabled the visualization of supraspinal, propriospinal and sensory circuits labeled with viral and nonviral tracers (Ni et al., 2014; Soderblom et al., 2015; Pocratsky et al., 2017; Wang et al., 2018; Hilton et al., 2019). Similar methods, albeit with the CLARITY technique, have been used to study reorganization of the cortico-reticulo-spinal pathway after SCI (Asboth et al., 2018). Thus, while promising, tissue clearing and $3 \mathrm{D}$ imaging techniques for the spinal cord remain underutilized as a common form of analysis. The optimization and validation of a simple clearing method for the intact and injured spinal cord could enhance the use of tissue clearing and $3 \mathrm{D}$ imaging for studying spinal cord neural circuits and secondary injury after SCI.

In this study, we optimized the PACT tissue clearing procedure to obtain gentle and efficient clearing of the murine spinal cord for 3D imaging by lightsheet microscopy. We demonstrate successful IF labeling and preservation of transgenic fluorescent proteins in cleared spinal cords, which enabled the visualization and quantification of multiple neuronal subtypes. We also validated our clearing procedures in the injured spinal cord to assess acute inflammation and long-term white matter loss. Finally, we show IF labeling for transplanted hiPSC-derived interneurons that enabled the complete visualization of transplant cell survival and axon extension in the intact and injured spinal cord. Collectively, these results show the promising utility of PACT tissue clearing for studying the intact and injured spinal cord.

\section{MATERIALS AND EQUIPMENT}

\section{Mouse Transcardial Perfusion and Dissection}

(1) Perfusion pump

(2) 32\% paraformaldehyde (Electron Microscopy Sciences, 15714-S)

(3) 10x phosphate-buffered saline (Corning $\left.{ }^{\circledR}, 20-031-\mathrm{CV}\right)$

(4) 15 mL conicals (Falcon ${ }^{\mathrm{TM}}, 352196$ )

(5) $50 \mathrm{~mL}$ conicals (Falcon ${ }^{\mathrm{TM}}, 352070$ )

(6) Surgical tools-fine tweezers (FST, 91115-10), adson forceps (FST, 91106-12), Metzenbaum scissors (FST, 14016-14), micro-scissors (FST, 15025-10).

\section{Hydrogel Polymerization}

(1) $15 \mathrm{~mL}$ conicals (Falcon $\left.{ }^{\mathrm{TM}}, 352196\right)$

(2) $40 \%$ acrylamide (Calbiochem, 1150-OP)

(3) VA-044 thermal initiator (FujiFilm, 011-19365)

(4) Parafilm (Parafilm ${ }^{\mathrm{TM}}$, PM996)

(5) Incubator-Ward's ${ }^{\circledR}$ mini digital incubator (Ward's Science $\left.^{\mathrm{TM}}, 470230-608\right)$

(6) Vacuum desiccator (SP Scienceware ${ }^{\mathrm{TM}}, \mathrm{F} 42025-0000$ )

(7) Compressed nitrogen

(8) Tube revolver (Thermo Scientific ${ }^{\mathrm{TM}}, 88881001$ ).

\section{Delipidation (Clearing)}

(1) Stirring hotplate (Thermo Scientific ${ }^{\mathrm{TM}}$, SP88854100)

(2) Boric acid (Fisher Chemical ${ }^{\mathrm{TM}}$, A73-500)

(3) Sodium hydroxide (Millipore Sigma, S8045)

(4) Sodium dodecyl sulfate (Fisher BioReagents, BP82005)

(5) Nutating rocker-LabDoctor ${ }^{\mathrm{TM}}$ Mini Nutating Rocker (Ward's Science $\left.{ }^{\mathrm{TM}}, \mathrm{H} 3 \mathrm{D} 1020\right)$

(6) Incubator-Ward's ${ }^{\circledR}$ Mini Digital Incubator (Ward's Science $\left.^{\mathrm{TM}}, 470230-608\right)$

(7) Parafilm (Parafilm ${ }^{\mathrm{TM}}$, PM996)

(8) Triton $^{\mathrm{TM}}$ X-100 (Alfa Aesar, A16046-AE)

(9) Tube revolver (Thermo Scientific ${ }^{\mathrm{TM}}, 88881001$ )

(10) $15 \mathrm{~mL}$ conicals (Falcon $\left.{ }^{\mathrm{TM}}, 352196\right)$.

\section{Immunohistochemistry (Optional)}

(1) Normal donkey serum (Millipore Sigma, D9663)

(2) Sodium azide (Millipore Sigma, S2002)

(3) $0.22 \mu \mathrm{m}$ syringe filter unit (Millex-GP, SLGP033RS) 
(4) $10 \mathrm{~mL}$ syringe (Fisherbrand $\left.{ }^{\mathrm{TM}}, 14955458\right)$

(5) $1.5 \mathrm{~mL}$ microcentrifuge tubes (Denville, C2170)

(6) $0.6 \mathrm{~mL}$ microcentrifuge tubes (Fisherbrand ${ }^{\mathrm{TM}}$, 05-408120)

(7) $15 \mathrm{~mL}$ conicals (Falcon $\left.{ }^{\mathrm{TM}}, 352196\right)$

(8) Primary antibodies - goat anti-ChAT (1:200, Millipore Sigma, AB144P), rabbit anti-NeuN (1:200, Millipore Sigma, ABN78), goat anti-S100A8 (MRP8, 1:500, R\&D Systems ${ }^{\mathrm{TM}}$, AF3059), mouse anti-hTau (1:500, BioLegend $^{\circledR}, 835201$ )

(9) Secondary antibodies (1:200) - Donkey anti-Goat IgG AlexaFluor ${ }^{\circledR} 488$ (Invitrogen, A32814), Donkey anti-Rabbit IgG AlexaFluor ${ }^{\circledR} 488$ (Invitrogen, A32790), Donkey anti-Mouse IgG AlexaFluor ${ }^{\circledR} 555$ (Invitrogen, A32773), Donkey anti-Rabbit IgG AlexaFluor ${ }^{\circledR} 647$ (Invitrogen, A32795), Donkey anti-Goat IgG AlexaFluor ${ }^{\circledR}$ 647 (Invitrogen, A32849).

\section{SWITCH DiD Labeling (Optional)}

(1) 10x phosphate-buffered saline (Corning $\left.{ }^{\circledR}, 20-031-C V\right)$

(2) Sodium dodecyl sulfate (Fisher BioReagents, BP82005)

(3) Triton $^{\mathrm{TM}}$ X-100 (Alfa Aesar, A16046-AE)

(4) DiD (Thermo Scientific $\left.{ }^{\mathrm{TM}}, \mathrm{D} 7757\right)$.

\section{Tissue Embedding and Refractive Index Equilibration}

(1) Sodium phosphate, monobasic, monohydrate (Millipore Sigma, S9638)

(2) Sodium phosphate, dibasic, anhydrous (Millipore Sigma, 567550)

(3) Agarose, low-melting (Millipore Sigma, A9045)

(4) 0.5 cc syringes $\left(\right.$ EXEL $\left.^{\circledR}, 26028\right)$

(5) $15 \mathrm{~mm} \times 85 \mathrm{~mm}$ culture tubes (Pyrex, 99445-15)

(6) Nycodenz (Alere Technologies, 1002424)

(7) Heat block with $1.5 \mathrm{~mL}$ adaptor

(8) PAL-RI pocket refractometer (Atago, 3850).

\section{METHODS}

\section{Animals}

Adult male and female C57Bl/6, Chx10-Cre, Ai14 [B6.CgGT(ROSA)26Sor TM14(CAG-tdTomato)Hze/J], and NOD scid gamma (NSG; NOC.Cg-Prkdc ${ }^{\text {scid }} \mathrm{Il}_{2} \mathrm{rg}^{\mathrm{TM} 1 \mathrm{Wjl}} / \mathrm{SzJ}$ ) mice were used for all studies. All studies were approved by the Institutional Animal Care and Use Committees at the University of California San Francisco, Texas A\&M University, and the Cincinnati Children's Hospital. All studies were in accordance with the United States Department of Agriculture guidelines.

\section{Spinal Cord Injury}

Adult ( $~ 3-5$ months) male and female mice were anesthetized with $2 \%$ isoflurane and a laminectomy was performed at the T9 to expose the spinal cord. A $70 \mathrm{kDyn}$ spinal cord contusion was delivered using the Infinite Horizons impactor. The musculature was sutured closed and the skin closed with wound clips. Manual bladder expression was performed twice daily and subcutaneous injections of saline and antibiotics (enrofloxacin, $2.5 \mathrm{mg} / \mathrm{kg}$ ) were given daily.

\section{V2a Interneuron Transplantation}

Human induced pluripotent stem cell-derived V2a interneurons were generated as previously described (Butts et al., 2019). For transplantation into the intact spinal cord, adult female NSG mice were anesthetized with $2 \%$ isoflurane and a laminectomy was performed at T9. The spinal column was secured using the IH spinal clamps and approximately 500,000 hiPSC-derived V2a interneurons were transplanted over four injections sites at a depth of $1 \mathrm{~mm}$ into the ventral grey matter at T9 using a glass micropipette attached to a Nanoject III (Drummond). In another cohort of NSG mice, the T9 laminectomy site was re-exposed at 14 days post-SCI and approximately 500,000 hiPSC-derived V2a interneurons were transplanted in the ventral grey matter bilaterally at a depth of $1 \mathrm{~mm}$ at the rostral and caudal aspects of T9. Following transplantation, the musculature and skin were closed and postoperative care was performed as described above for SCI.

\section{PACT Tissue Clearing and Immunofluorescent Labeling}

See Table 1 for troubleshooting PACT clearing of the mouse spinal cord.

\section{Mouse Transcardial Perfusion-Fixation}

Purpose: Transcardial perfusion helps remove peripheral blood, which can lead to undesired background fluorescent signal in the vasculature, and provides rapid and even preservation of spinal cord tissue.

1. Prepare $1 \mathrm{x}$ PBS and $4 \%$ paraformaldehyde in $1 \mathrm{x}$ PBS $(\mathrm{pH}$ 7.4) solutions and place on ice.

Caution: Paraformaldehyde is a carcinogenic agent. Ensure to take the proper handling precautions; perform all procedures in a fume hood. Paraformaldehyde waste should be discarded according to institutional protocols.

2. Perfuse mouse with $25 \mathrm{~mL}$ of ice-cold 1x PBS followed by $25 \mathrm{mLs}$ of ice-cold $4 \%$ paraformaldehyde in PBS.

3. Dissect out the spinal column using Metzenbaum scissors and Adson forceps. Transfer the spinal column to $10 \mathrm{~mL}$ of ice-cold $4 \%$ paraformaldehyde in $1 \mathrm{x}$ PBS in a $15 \mathrm{~mL}$ conical and post-fix $\mathrm{O} / \mathrm{N}$ at $4^{\circ} \mathrm{C}$.

4. The following day, transfer the spinal column to $40 \mathrm{~mL}$ of ice-cold $1 \mathrm{x}$ PBS in a $50 \mathrm{~mL}$ conical and store $\mathrm{O} / \mathrm{N}$ at $4^{\circ} \mathrm{C}$.

Checkpoint: Possible stopping point - tissue may be stored in $1 \mathrm{x}$ PBS with $0.01 \%(\mathrm{w} / \mathrm{v})$ sodium azide at $4{ }^{\circ} \mathrm{C}$ for several weeks.

\section{Spinal Cord Dissection and Meninges Removal}

Purpose: Clean dissection of the spinal cord tissue is critical for uniform tissue clearing and IF labeling. Removal of the meninges helps accommodate tissue swelling during the clearing procedure and enables greater diffusion into and out of the spinal cord parenchyma. 
TABLE 1 | Troubleshooting PACT clearing of the whole mouse spinal cord.

Problem Possible cause and solution

Hydrogel does not become viscous after polymerization

Hydrogel is highly viscous or solid after polymerization

The spinal cord tissue is clearing at a slow rate ( $>7$ days) or does not fully clear prior to degrading in SDS

Spinal cord tissue rapidly clears ( $<3$ days) and/or degrades in SDS

Spinal cord tissue becomes opaque after washing out the SDS (see section "Delipidation (Clearing)," Steps 7-9) Transgenic/endogenous fluorescent proteins are dim or not observed after clearing

IF labeling is not uniform (brighter on the outside of the tissue than in the center)

Tissues are degrading (falling apart) during or after the IF labeling steps

Poor IF labeling is observed for antibodies previously validated in tissue sections

IF labeling is uniform and present, but dim

Air bubbles form in agarose during mounting
Poor hydrogel polymerization may be caused by insufficient degassing of the sample. Alternatively, the incorrect concentration of acrylamide or VA-044 (thermal initiator) may have been used. Use a stronger vacuum source (100-150 Torr) and confirm that the correct concentration of acrylamide (4\%) and VA-044 (0.25\%) is used. Replace the reagents if polymerization is still inadequate.

If bis-acrylamide is present in the acrylamide reagent, then the hydrogel may become highly viscous or solid. Rocking or rotating the sample during polymerization may also increase cross-linking. Verify that the acrylamide reagent does not contain bis-acrylamide. Perform the hydrogel polymerization with the conical upright in the $37^{\circ} \mathrm{C}$ incubator. Confirm that the correct concentration of acrylamide (4\%) and VA-044 (0.25\%) is used.

There are several potential causes of poor clearing of spinal cord tissue. Over-fixation can dramatically reduce the efficacy of clearing, as such we recommend limiting the post-fixation of spinal cords to overnight. Incomplete removal of meninges may also contribute to poor clearing. The spinal cord tissue should partially swell during clearing. If there are areas where the spinal cord swelling appears constricted, then the meninges may not have been fully removed. If the clearing is still slow, reduce the hydrogel polymerization time to $2 \mathrm{~h}$. The described procedure has been optimized for murine spinal cord tissue and may not work for spinal cord tissue from other species (such as rats).

If the spinal cord tissue is rapidly clearing and/or degrading during the delipidation phase, this may be caused by poor fixation. We recommend making fresh fixative and ensure that adequate fixation is occurring during the perfusion and post-fixation steps.

Spinal cord tissue will become slightly opaque during the washing process due to mismatches in refractive indices between the tissue $(\mathrm{RI} \sim 1.45)$ and buffer $(\mathrm{RI} \sim 1.33)$. The tissue should return to a transparent state during refractive index equilibration. If the tissue remains opaque, the tissue may need longer clearing time or additional washes in Section "Delipidation (Clearing)," Steps 7-9.

Some transgenic fluorescent proteins, including eGFP and mCherry, can be quenched by the PACT clearing procedure. Antigenically distinct fluorescent proteins that have been quenched during clearing can be visualized by IF labeling. If possible, we recommend using fluorescent proteins that have been previously shown to withstand PACT clearing, such as tdTomato. Also, ensure that samples are protected from light at all times during the tissue clearing, IF labeling, and imaging procedures.

With highly abundant epitopes, antibodies used for IF labeling may be depleted before they can reach the center of the tissue. We recommend testing different antibody sources, using alternative markers, or utilizing methods to sub-maximally label epitopes (such as SWITCH).

It is critical to add sodium azide after tissue clearing as the tissue can become infected and rapidly degrade at RT. If the problem persists, we recommend increasing the sodium azide to $0.02 \%(\mathrm{w} / \mathrm{v})$ or testing an alternative source of sodium azide.

The delipidation process of tissue clearing utilizes SDS, which can denature or remove certain epitopes. This is particularly common for cell surface biomolecules. All antibodies will need to be re-evaluated in cleared tissues. Titration of the antibody concentration for IF labeling in cleared tissues will also need to be performed since a greater total amount of antibody is typically needed to label whole cleared spinal cords. If poor IF labeling is observed with antibodies validated in cleared tissues, we recommend increasing the washing steps after clearing as precipitated SDS can impact IF labeling. If poor IF labeling persists, we recommend testing a different source of the antibody or identifying alternative markers.

Increase the total amount of primary and/or secondary antibodies used. Whole cleared spinal cord tissue will often require $2-10 \times$ the total amount of antibody typically used for traditional IF labeling on tissue sections. Also, ensure that samples are protected from light at all times once the tissues have been labeled with fluorescent primary or secondary antibodies.

Air bubbles can often form at the interface of the agarose and cleared tissue during the mounting procedure and will markedly reduce image quality. To reduce bubble formation, wash the samples in a separate solution of agarose prior to mounting.
1. Dissect the spinal cord from the spinal column.

1.1 Starting at the cervical end of the cord, locate the interior of the spinal column and carefully make lateral incisions using micro-scissors on both sides of the ventral aspect of the first vertebra.

Note: Micro-scissors should be oriented flat along the ventral side of the vertebra to prevent damage to the spinal cord.

1.2 Using fine tweezers, peel off the cut portion of the vertebra to expose the spinal cord. Repeat for each vertebra down the entire length of the cord.
2. Remove spinal cord from spinal column.

2.1 Starting at the lumbar end of the cord, sever the spinal nerves that anchor the cord in the column. Carefully peel away the spinal cord from the rest of the column.

2.2 Remove hair, bone fragments, and debris adhered to the spinal cord.

3. Remove the meninges.

3.1 Transfer the spinal cord to petri dish. Starting at either end of the spinal cord, carefully peel off the 
meninges using fine forceps while holding onto the spinal cord with adson forceps.

Note: Occasionally wet the spinal cord with $1 x$ PBS as needed to prevent tissue from drying out. Removal of meninges is a critical step toward faster and uniform clearing. Take special care not to tug on the meninges as such force will result in severing the tissue.

4. Transfer the dissected spinal cord to $14 \mathrm{~mL}$ of ice-cold $1 \mathrm{x}$ PBS in a $15 \mathrm{~mL}$ conical.

Checkpoint: Possible stopping point - tissue may be stored in $1 \mathrm{x}$ PBS with $0.01 \%(\mathrm{w} / \mathrm{v})$ sodium azide at $4^{\circ} \mathrm{C}$ for several weeks.

\section{Hydrogel Polymerization}

Purpose: The hydrogel-tissue crosslinking helps preserve endogenous epitopes and biomolecules for subsequent labeling procedures. Creating a hydrogel-tissue hybrid can also improve the uniformity of the refractive indices throughout the tissue for greater clarity during lightsheet imaging.

1. Prepare $12.5 \mathrm{~mL} / \mathrm{sample}$ of A4P0 (4\% acrylamide $+0 \%$ paraformaldehyde) monomer solution.

1.1 For $40 \mathrm{~mL}$ of solution, combine $4 \mathrm{~mL}$ of $10 \mathrm{x}$ PBS and $4 \mathrm{~mL}$ of $40 \%$ acrylamide in $32 \mathrm{~mL}$ of ice-cold $\mathrm{ddH}_{2} \mathrm{O}$.

1.2 Chill on ice for $30 \mathrm{~min}$.

1.3 Dissolve $100 \mathrm{mg}$ of VA-044 thermal initiator in the chilled $4 \%$ acrylamide in $1 x$ PBS solution.

Caution: Acrylamide is a carcinogenic agent. Always ensure proper handling precautions, work with acrylamide in a fume hood. Acrylamide waste should be discarded according to institutional protocols.

2. Transfer the spinal cord to $12.5 \mathrm{~mL}$ of ice-cold A4P0 monomer solution in a $15 \mathrm{~mL}$ conical.

3. Seal with parafilm around the cap of conical to prevent leakage. Secure conical horizontally to a tray that can contain any potential leaks.

4. Incubate $\mathrm{O} / \mathrm{N}$ at $4^{\circ} \mathrm{C}$ with gentle rocking on a nutating rocker.

Note: Place the conical flat on the nutating rocker such that the spinal cord tissue partially inverts during rocking. The movement of the spinal cord tissue during inversion will facilitate penetration of the A4P0 hydrogel.

5. Transfer the conical containing the spinal cord to a fume hood, remove parafilm, and uncap the conical. Place the uncapped conical upright in a tube rack within a vacuum desiccator and purge the spinal cord of residual oxygen for $30 \mathrm{~min}$. Occasionally tap the desiccator to dislodge bubbles.

6. Flood the dessicator with nitrogen for 1-2 $\mathrm{min}$ and then cap the conical inside the desiccator. Seal the conical with parafilm.

7. Incubate the conical with the spinal cord tissue upright in pre-heated $37^{\circ} \mathrm{C}$ incubator for $3 \mathrm{~h}$.

8. Remove the sample from the polymerized hydrogel solution.
Note: Solution should be viscous, but will still flow when the conical is inverted.

9. Wash the sample in $14 \mathrm{~mL}$ of $1 \mathrm{x}$ PBS in a new $15 \mathrm{~mL}$ conical on a tube revolver for $5 \mathrm{~min}$ at $\mathrm{RT}$.

\section{Delipidation (Clearing)}

Purpose: The delipidation procedure removes the majority of lipids that can cause light scattering and tissue opacity during lightsheet imaging.

1. Prepare $1 \mathrm{M}$ boric acid buffer $(\mathrm{pH}=8.5)$

1.1 Dissolve $61.83 \mathrm{~g}$ of boric acid and $12 \mathrm{~g}$ of sodium hydroxide pellets $(\mathrm{NaOH})$ in $900 \mathrm{~mL}$ of $\mathrm{ddH}_{2} \mathrm{O}$. Stir until fully dissolved and clear. Add $\mathrm{ddH}_{2} \mathrm{O}$ up to final volume of $1 \mathrm{~L}$.

2. Make $10 \%$ SDS in water $(\mathrm{w} / \mathrm{v})$.

2.1 Dissolve $100 \mathrm{~g}$ of SDS micropellets (Fisher BioReagents, BP82005) in $800 \mathrm{~mL}$ of $\mathrm{ddH}_{2} \mathrm{O}$. Stir constantly over heat up to $60^{\circ} \mathrm{C}$. When solution is clear, turn off heat and cool to RT. Add dd $\mathrm{H}_{2} \mathrm{O}$ up to final volume of $1 \mathrm{~L}$.

Caution: SDS is a corrosive irritant. Always ensure the proper handling precautions; make solution and perform all solution changes in a fume hood. SDS waste should be discarded according to institutional protocols.

3. Prepare $12.5 \mathrm{~mL} /$ sample of $8 \%$ SDS in $0.2 \mathrm{M}$ boric acid buffer (SDS clearing solution) by combining $10 \mathrm{~mL}$ of $10 \%$ SDS with $2.5 \mathrm{~mL}$ of $1 \mathrm{M}$ boric acid buffer.

Note: Do not store the SDS clearing solution at RT for more than 1 day since SDS may precipitate in boric acid buffer.

4. Transfer tissue from PBS to $12.5 \mathrm{~mL}$ of SDS clearing solution in a $15 \mathrm{~mL}$ conical. Seal lid with parafilm and incubate at $37^{\circ} \mathrm{C}$ on a nutating rocker.

Note: Place the conical flat on the nutating rocker such that the sample partially inverts and moves toward each end of the conical during rocking. The movement of the spinal cord tissue will facilitate removal of lipids.

Note: Samples with endogenous or transgenic fluorescent signals should be protected from light during delipidation and washing.

5. Replace SDS clearing solution every other day until the spinal cord is optically transparent. Full-length mouse spinal cord tissue should clear in 5-7 days.

Note: Avoid leaving spinal cord tissues in SDS clearing solution after becoming optically transparent, as this can lead to sample degradation.

6. Prepare $0.2 \mathrm{M}$ BBT.

6.1 Combine $800 \mathrm{~mL}$ of $\mathrm{ddH}_{2} 0,200 \mathrm{~mL}$ of $1 \mathrm{M}$ boric acid buffer, and $1 \mathrm{~mL}$ of Triton ${ }^{\mathrm{TM}} \mathrm{X}-100$. Stir at RT until all components are fully dissolved.

7. Once the spinal cord has finished clearing, transfer to $14 \mathrm{~mL}$ of BBT in a $15 \mathrm{~mL}$ conical and rotate at RT for $30 \mathrm{~min}$ on tube revolver to wash out the residual SDS.

8. After $30 \mathrm{~min}$, replace the BBT solution and continue rotating.

9. Repeat Step 8 four times then leave the sample in BBT solution $\mathrm{O} / \mathrm{N}$ rotating at $\mathrm{RT}$. 
Note: Rapid washing of the SDS solution is critical to preventing precipitation of SDS inside the sample, which reduces optical clarity and efficiency of IF labeling. The sample may become slightly opaque after washing, but should remain transparent.

Checkpoint: Possible stopping point - tissue may be stored in BBT or $0.2 \mathrm{M}$ boric acid buffer with $0.01 \%$ sodium azide at $4^{\circ} \mathrm{C}$.

\section{Immunofluorescent (IF) Labeling}

Purpose: IF labeling enables the visualization and analysis of endogenous or transgenic epitopes within the cleared spinal cord tissue.

1. Prepare staining buffer: BBT $+2 \%(\mathrm{v} / \mathrm{v})$ normal donkey serum $(\mathrm{NDS})+0.01 \%(\mathrm{w} / \mathrm{v})$ sodium azide.

2. Prepare primary antibodies in staining buffer $(\sim 1 \mathrm{~mL} /$ sample).

3. Transfer the spinal cord tissue into the staining buffer with primary antibodies in a $1.5 \mathrm{~mL}$ MCT. Protect from light and rotate for 2 days at RT on tube revolver.

Note: For small spinal cord tissues, transfer sample to $\sim 500 \mu \mathrm{L}$ of staining buffer with primary antibodies in a $0.6 \mathrm{~mL}$ MCT.

Note: Spinal cord tissues should invert during rotation on the tube revolver, which will improve the penetration of antibodies. Two days is usually sufficient for antibodies to diffuse to the center of the spinal cord samples. Steps 1-3 can be repeated if necessary.

4. Transfer spinal cord tissue to $14 \mathrm{~mL}$ of BBT solution with $0.01 \%(\mathrm{w} / \mathrm{v})$ sodium azide in a $15 \mathrm{~mL}$ conical and wash tissue with five buffer changes within $3-5 \mathrm{~h}$ on a tube revolver at RT. Leave the sample in the last wash $\mathrm{O} / \mathrm{N}$ on a tube revolver at RT.

Note: From this point on, it will be crucial to add sodium azide to a final concentration of at least $0.01 \%$ to every solution to prevent infection/contamination of the sample.

5. Prepare secondary antibodies in staining buffer ( $\sim 1.2 \mathrm{~mL} /$ sample).

6. Filter staining buffer with secondary antibodies using syringe filter to remove any aggregates of secondary antibody that may affect IF labeling.

7. Transfer spinal cord tissue to $1 \mathrm{~mL}$ of filtered antibody solution in a $1.5 \mathrm{~mL}$ MCT. Protect from light and rotate for 2 days at RT on tube revolver.

Note: For smaller tissues, prepare $\sim 700 \mu \mathrm{L}$ of staining buffer with secondary antibodies. Transfer smaller tissue to $\sim 500 \mu \mathrm{L}$ of filtered antibody solution in a $0.6 \mathrm{~mL}$ MCT.

8. Repeat Step 4.

Checkpoint: Possible stopping point - spinal cord tissue may be stored in BBT with $0.01 \%$ sodium azide at $4^{\circ} \mathrm{C}$ protected from light.

\section{Tissue Embedding and Refractive Index Equilibration}

Purpose: Tissue embedding is critical for safe handling of the sample during lightsheet imaging. RI equilibration helps reduce RI mismatches in or with the spinal cord tissue to minimize the diffraction or scattering of light, thereby improving image clarity.

1. Prepare 0.1 M PB, pH 7.4.

1.1 Dissolve $3.1 \mathrm{~g}$ of sodium phosphate $\left(\mathrm{NaH}_{2} \mathrm{PO}_{4}\right.$, monobasic, monohydrate) and $10.9 \mathrm{~g}$ of sodium phosphate $\left(\mathrm{Na}_{2} \mathrm{HPO}_{4}\right.$, dibasic, anhydrous) in $900 \mathrm{~mL}$ of $\mathrm{ddH}_{2} \mathrm{O}$. Add $\mathrm{ddH}_{2} \mathrm{O}$ up to final volume of $1 \mathrm{~L}$.

2. Prepare $0.02 \mathrm{M} \mathrm{PB}$ ( $\mathrm{pH} 7.4$ ) by combining $200 \mathrm{~mL}$ of $0.1 \mathrm{M}$ $\mathrm{PB}$ and $800 \mathrm{~mL}$ of $\mathrm{ddH}_{2} \mathrm{O}$.

3. Prepare $1.5 \%$ agarose solution by dissolving $300 \mathrm{mg}$ of lowmelt agarose in $20 \mathrm{~mL}$ of $0.02 \mathrm{M} \mathrm{PB}$.

3.1 Microwave solution in 10-15 s intervals until agarose is fully dissolved.

3.2 Allow solution to cool to approximately $50^{\circ} \mathrm{C}$ and aliquot $1 \mathrm{~mL}$ into $1.5 \mathrm{~mL}$ MCTs and place on a heat block set at $42^{\circ} \mathrm{C}$.

Note: Extra agarose aliquots may be stored at $4^{\circ} \mathrm{C}$, remelted on a heat block at $95^{\circ} \mathrm{C}$, and cooled to $42^{\circ} \mathrm{C}$.

4. Cut off the needle tip of a $0.5 \mathrm{cc}$ insulin syringe such that the full internal diameter of the syringe is exposed. Pull up approximately 250-300 uL of agarose solution into the syringe.

5. Wash the sample by briefly placing in the agarose solution, then moving to a new MCT with agarose solution. Draw up the sample + agarose solution into the second half of the syringe. The syringe should be nearly full of agarose solution with the sample located near the tip of the syringe. Note: Ensure that there are no air bubbles around the tissue or near the plunger that may hinder imaging or cause the sample to slip out of the syringe, respectively.

6. Allow agarose solution to solidify protected from light for a minimum of $1 \mathrm{~h}$ at RT.

7. Prepare enough RIMS to equilibrate samples in $5 \mathrm{~mL}$ each and to fill the sample chamber for lightsheet imaging.

7.1 For $\sim 40 \mathrm{~mL}$ of RIMS, dissolve $30 \mathrm{~g}$ of Nycodenz in $22.5 \mathrm{~mL}$ of $0.02 \mathrm{M}$ PB in a $50 \mathrm{~mL}$ conical. Place on a tube revolver for several hours at RT until fully dissolved.

7.2 Add sodium azide to a final concentration of $0.01 \%$.

7.3 Measure the RI of the RIMS using a refractometer.

Note: Use $600 \mu \mathrm{L}$ volumes for measuring the RI with the PAL-RI pocket refractometer.

7.4 Adjust the RI of the RIMS with Nycodenz (for low RIs) or $0.02 \mathrm{~PB}$ (for high RIs) until the RI is between 1.455 and 1.458 . Store at $4^{\circ} \mathrm{C}$.

8. Place the syringe in $5 \mathrm{~mL}$ of RIMS in a $15 \mathrm{~mm} \times 85 \mathrm{~mm}$ culture tube.

9. Center the syringe in the opening of the culture tube and use parafilm to secure in place such that the tip of the syringe is just below the surface of RIMS.

10. Eject the embedded sample into the RIMS so that it is surrounded by the RIMS with the remaining agarose still inside of the syringe. 
11. Equilibrate sample for 1-2 days in the dark at RT. Sample is ready to image once the sample and agarose are optically transparent in the RIMS.

Note: Mounted tissue may be washed with $0.2 \mathrm{M}$ boric acid buffer for $1 \mathrm{~h}$, gently removed from the agarose, and restained/re-mounted or stored in $0.2 \mathrm{M}$ boric acid buffer with $0.01 \%$ sodium azide at $4^{\circ} \mathrm{C}$.

Checkpoint: Possible stopping point - mounted tissues may be stored in RIMS with $0.01 \%$ sodium azide at $4^{\circ} \mathrm{C}$.

\section{DiD Labeling}

Spinal cord samples were incubated in $10 \mathrm{mM}$ SDS in PBS (SWITCH-off) $\mathrm{O} / \mathrm{N}$ at $37^{\circ} \mathrm{C}$ with gentle rocking before incubating with $\mathrm{DiD}(5 \mathrm{ug} / \mathrm{mL})$ in SWITCH-off buffer $\mathrm{O} / \mathrm{N}$ at $37^{\circ} \mathrm{C}$ with gentle rocking (Murray et al., 2015). Spinal cord samples were then washed in PBS with $0.01 \%$ triton (SWITCHon) $\mathrm{O} / \mathrm{N}$ at $37^{\circ} \mathrm{C}$ with gentle rocking.

\section{Lightsheet Imaging}

Prior to imaging, spinal cords were mounted in $1-2 \%$ agarose inside of $0.5 \mathrm{~mL}$ syringes. After solidification of the agarose, spinal cords were suspended in RI matching solution (RIMS; $30 \mathrm{~g}$ of Nycodenz in $0.02 \mathrm{M} \mathrm{PB}$ with $0.01 \%$ sodium azide; $\mathrm{RI}=1.458$ ) for 2 days. After equilibration in RIMS, spinal cord samples were imaged using a Zeiss Z1 lightsheet microscope equipped with a $5 \times$ objective. Image $Z$-stacks were captured for both left and right sided lightsheet illumination using Zen software. Dual side fusion of left- and right-sided images was performed in Zen software.

\section{Image Processing and Analysis}

Maximum intensity projections of image Z-stacks were generated using Zen software. Composite MIP images were stitched from individual MIPs in Photoshop (Adobe). Image Z-stacks were visualized in Imaris 3D software (Bitplane). 3D videos were generated using the animation tool in Imaris. Soma and neutrophil quantification were performed using the spot assay in Imaris.

\section{Flow Cytometry}

Spinal cord tissue from adult female and male C57Bl/6 mice ( $n=2$ and 3 , respectively) was collected at 1 day post-SCI and processed for flow cytometry as previously described (McCreedy et al., 2018). Mechanically dissociated spinal cord tissue was first labeled with CD11b-APC/Cy7, Ly6C-PerCP/Cy5.5, and Ly6G-Pacific Blue for $30 \mathrm{~min}$ to identify myeloid lineage cells, monocytes, and neutrophils. Samples were then fixed, permeabilized, and incubated with MRP8 antibody (1:2000) for $30 \mathrm{~min}$. A separate portion of the dissociated spinal cord samples was incubated without MRP8 antibody as a primary antibody control (No $1^{\circ} \mathrm{Ab}$ ). After washing, all samples were incubated with donkey antigoat AlexaFluor ${ }^{\circledR} 488$ secondary antibody (1:500) for $30 \mathrm{~min}$. Samples were washed again and run on a BD Fortessa flow cytometer. Analysis for flow cytometry data was performed using FlowJo.

\section{Vibratome Sectioning and Confocal Microscopy}

Cleared spinal cord tissue, previously labeled with goat antiChAT and donkey anti-goat AlexaFluor ${ }^{\circledR} 647$ antibodies (see section "PACT Tissue Clearing and Immunofluorescent Labeling"), was cut into $5 \mathrm{~mm}$ segments and mounted in $2 \%$ agarose. Transverse sections (100 $\mu \mathrm{m}$ thickness) were obtained using a Leica VT1000S vibratome. Sections were mounted on glass slides and imaged using an Olympus FV1000 confocal microscope equipped with a $10 \times$ objective $(\mathrm{NA}=0.4)$.

\section{Cryosectioning and Traditional Immunofluorescent Labeling}

Uninjured spinal cord tissue was collected following transcardial perfusion and fixation as described in Section "Mouse Transcardial Perfusion-Fixation". A $5 \mathrm{~mm}$ segment of thoracic spinal cord tissue was cryoprotected in $30 \%$ sucrose in PBS, embedded, and frozen at $-80^{\circ} \mathrm{C}$. Transverse sections $(25 \mu \mathrm{m}$ thickness) were then obtained using a cryostat. Sections were permeabilized in $0.5 \%$ Triton X-100 in PBS, blocked with $5 \%$ NDS in PBS with $0.3 \%$ Triton $\mathrm{X}-100$, and labeled $\mathrm{O} / \mathrm{N}$ with goat anti-ChAT antibody (1:500) in 2\% NDS in PBS with $0.3 \%$ Triton X-100 at $4^{\circ} \mathrm{C}$. Sections were then washed and labeled with donkey anti-goat AlexaFluor ${ }^{\circledR} 647$ antibody (1:500) for $2 \mathrm{~h}$ at RT. Images were captured using a Nikon Eclipse upright microscope equipped with a $10 \times$ objective $(\mathrm{NA}=0.45)$.

\section{RESULTS}

\section{Rapid and Efficient Clearing of Spinal Cord Tissue Through Optimization of PACT}

Previous protocols for PACT describe a broad range of conditions to accommodate the clearing of many different tissues (Yang et al., 2014; Treweek et al., 2015). In this study, our goal was to optimize the conditions of the PACT procedure to enable reproducible clearing and IF labeling in the mouse spinal cord (Figure 1A). With the optimized PACT procedures (see Methods for details), whole mouse spinal cords were efficiently cleared in approximately 6 days (Figure 1B). Cleared spinal cords became fully transparent after 2 days of incubation in RIMS. Since no specialized equipment is required, multiple samples can be cleared in parallel to achieve high throughput processing. Passive clearing using hydrophilic and hydrogelbased techniques often require multiple weeks to months to achieve complete transparency (Tomer et al., 2014; Zhang et al., 2014; Woo et al., 2016), thus the optimized PACT procedure provides a simple and rapid method to passively clear the mouse spinal cord.

To determine the efficacy of IF labeling after PACT clearing, we incubated the cleared spinal cords with antibodies against ChAT and NeuN, followed by AlexaFluor-conjugated secondary antibodies, and imaged the samples using lightsheet microscopy. 
A

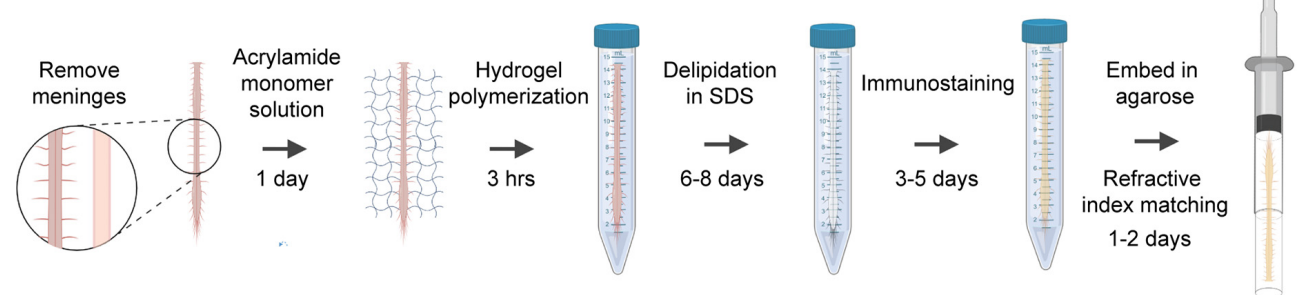

B

Days in SDS (lipid removal)
Day $0 \quad$ Day $2 \quad$ Day $4 \quad$ Day 6
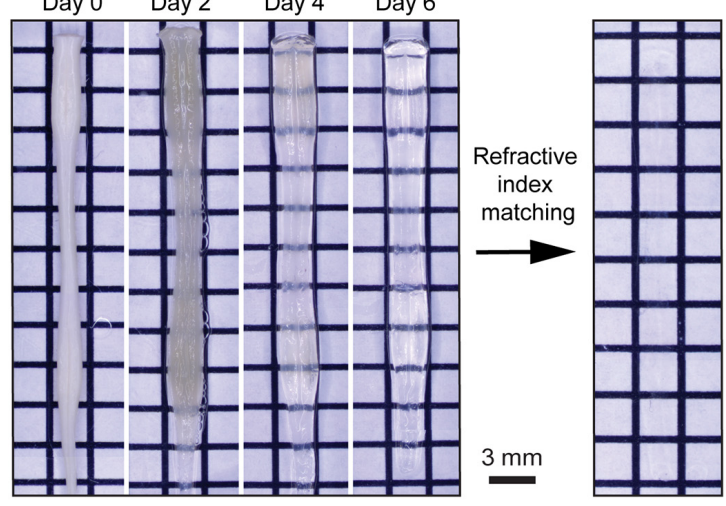

C

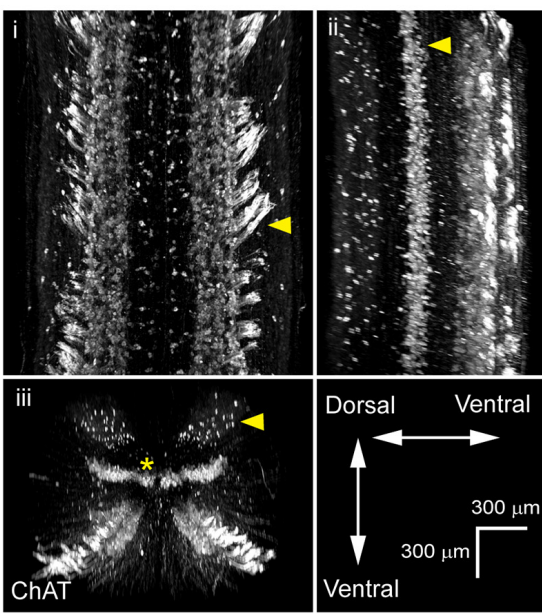

D
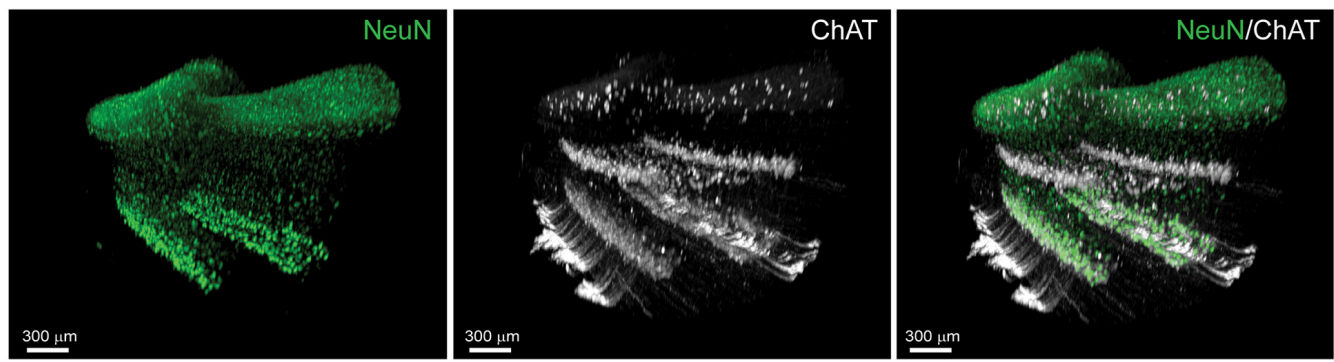

E
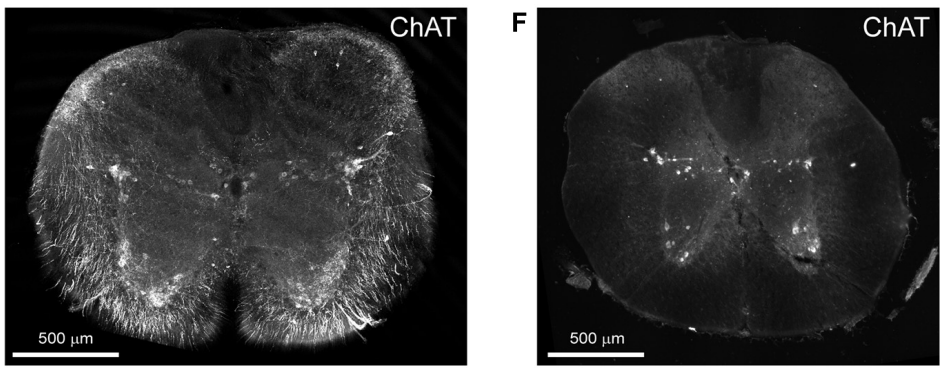

FIGURE 1 | Optimization of PACT procedures enables efficient clearing and IF labeling of the murine spinal cord. (A) Schematic of the optimized PACT clearing and IF labeling procedures. Created with BioRender. (B) Macroscopic images of tissue clearing of an intact spinal cord from a C57Bl/6 mouse with the optimized PACT procedures. (C) 3D projections of ChAT IF labeling with the optimized PACT protocol in the thoracic mouse spinal cord from dorsal (i), sagittal (ii), and transverse (iii) views. Arrows indicate motor axons, cholinergic neurons in the intermediate zone, and dorsal cholinergic interneurons, respectively. Asterisk indicates putative VOc interneurons in the medial region of the intermediate zone. (D) 3D projection of NeuN (green) and ChAT (white) IF labeling in the cleared thoracic mouse spinal cord. (E) Image of a vibratome section from cleared thoracic spinal cord tissue with ChAT (white) IF labeling that was performed in the whole cleared spinal cord prior to sectioning. (F) Image of traditional IF labeling for ChAT (white) performed on cryosections from thoracic spinal cord tissue that was not cleared. ChAT, choline acetyl transferase; IF, immunofluorescent.

In the 3D images, robust labeling of several cholinergic $\left(\mathrm{ChAT}^{+}\right)$ cell populations was observed (Figure 1C and Supplementary Movie 1). Motor neurons were readily apparent in the ventral grey matter and groups of motor axons were seen extending away from the ventral horn toward the ventral roots (Figure 1Ci, arrow). Additional cholinergic populations were observed in 


\section{A}

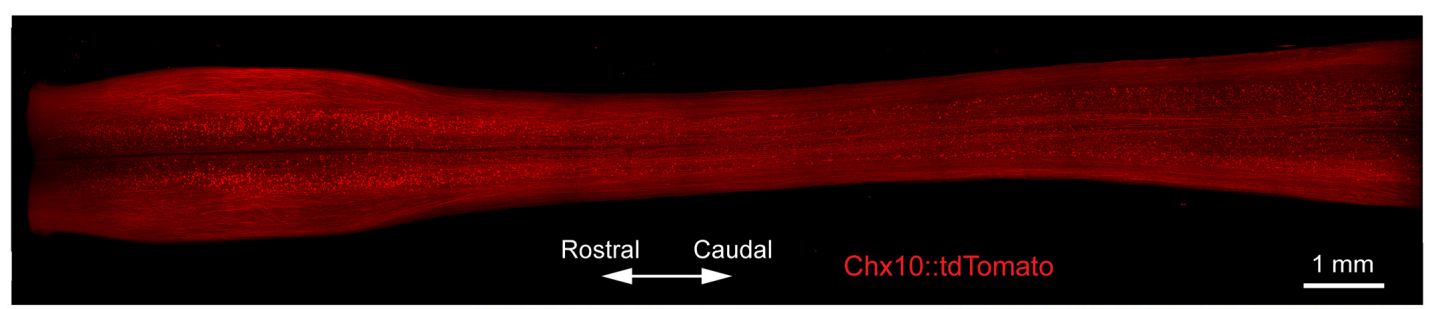

B
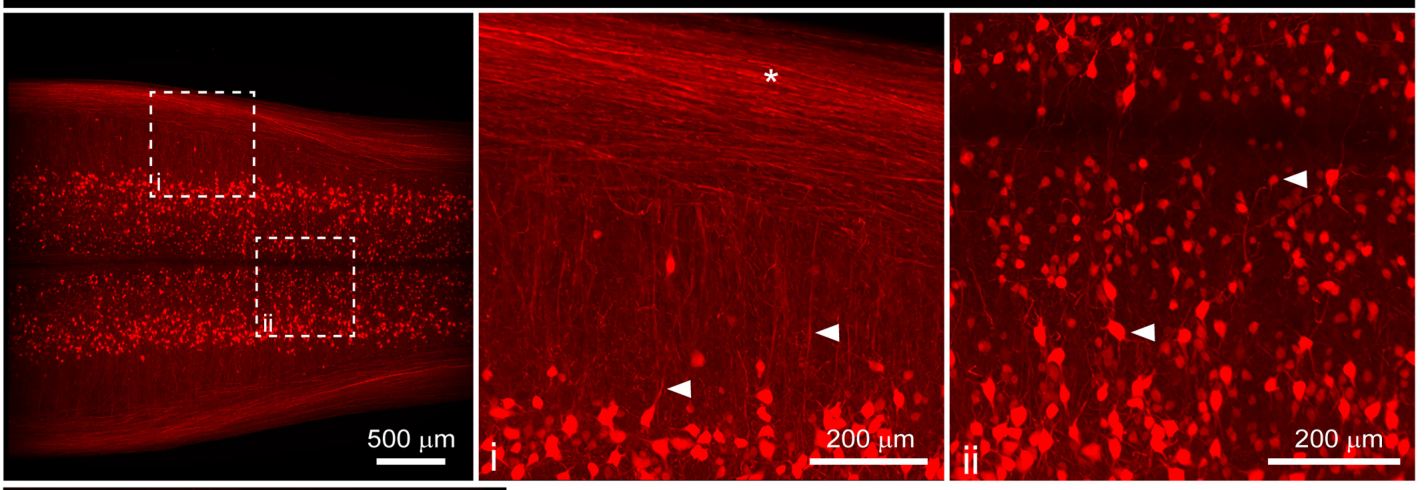

C

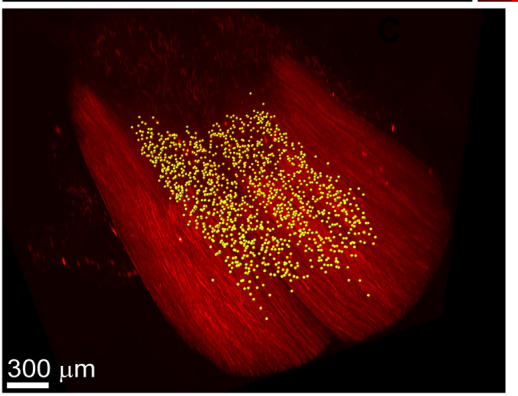

D

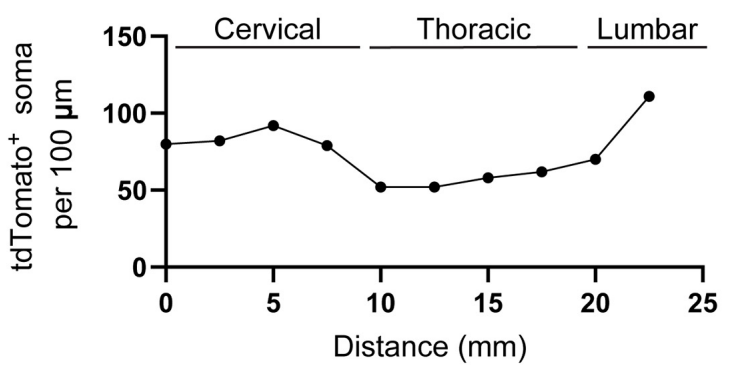

FIGURE 2 | PACT clearing preserves endogenous tdTomato fluorescence in spinal cord interneurons for 3D imaging of neural circuits. (A) Maximum intensity projection of tdTomato in V2a interneurons in the cleared spinal cord from a Chx10:tdTomato mouse. (B) Maximum intensity projection of the intermediate zone from a single field of view of the cleared spinal cord showing V2a interneuron soma. Axons from V2a interneurons project laterally in the grey matter before extending along white matter tracts (i; arrows and asterisk, respectively). Large and small soma can be easily identified (ii, arrows) in the grey matter. (C) V2a interneuron soma counting in Imaris (yellow dots). (D) Average number of V2a interneurons per $100 \mu \mathrm{m}$ assessed every $2.5 \mathrm{~mm}$ along the length of the spinal cord $(n=1)$.

the intermediate zone (Figure 1Cii, arrow), which may include a medial V0c interneuron population (Figure 1Ciii, asterisk) as well as a lateral population of sympathetic pre-ganglionic neurons in the intermediolateral nuclei. We also found a sparse cholinergic dorsal interneuron population (Figure 1Ciii, arrow), which has been previously described (Pawlowski et al., 2013). Specific IF labeling of NeuN was also observed, which enabled the assessment of NeuN and ChAT co-localization to confirm the grey matter location and neuronal identity of $\mathrm{ChAT}^{+}$ cells (Figure 1D).

To further assess the efficacy of IF labeling in whole cleared spinal cords, we first performed IF labeling for ChAT in cleared spinal cord tissue and then obtained transverse sections from the thoracic region of the labeled tissue using a vibratome. We observed ChAT staining throughout the white and grey matter of the spinal cord, including near the central canal, demonstrating that antibodies can diffuse to the center of the tissue when IF labeling is performed in whole cleared spinal cords (Figure 1E). Traditional IF labeling of ChAT was also performed on transverse cryosections of spinal cord tissue that had not been cleared (Figure 1F). These data demonstrate bright IF labeling for easy detection of neuronal subclasses using cell-type specific markers in cleared spinal cord tissue.

\section{PACT Clearing Preserves Transgenic Fluorescence for 3D Imaging of Spinal Cord Neural Circuits}

To determine the compatibility of the optimized PACT protocol with transgenic fluorescent protein signals in the murine spinal cord, we bred Chx10-Cre mice with the Ai14 reporter mice to generate offspring (Chx10:tdTomato mice) with tdTomato expression in V2a interneurons. Using lightsheet microscopy, we imaged the majority of the length of the cleared spinal cord (C1-L1) by stitching together multiple fields of view. Transgenic tdTomato fluorescent signal was well-preserved in V2a interneuron soma and axons in the cleared spinal cords of Chx10:tdTomato mice (Figure 2A and Supplementary Movie 2). We observed tdTomato ${ }^{+} \mathrm{V} 2 \mathrm{~A}$ interneuron soma distributed 
throughout the grey matter at all levels of the spinal cord, as well as extensive tdTomato ${ }^{+}$axon tracts in the ventral spinal cord that spanned the length of the imaged region.

To digitally isolate V2a interneurons for further analysis, we acquired MIPs of the $z$-stack image planes spanning the intermediate zone of the spinal cord including most of laminae VII (Figure 2B). We observed tdTomato ${ }^{+}$axons from V2a interneurons extending laterally through the grey matter before joining tdTomato ${ }^{+}$axon tracts in the spinal cord white matter (Figure 2Bi; arrows and asterisk, respectively). In addition, heterogeneity in tdTomato $^{+} \mathrm{V} 2 \mathrm{a}$ interneuron soma size and location along the medialateral axis of the spinal cord was readily observed (Figure 2Bii, arrows). We quantified tdTomato ${ }^{+}$ soma numbers using Imaris software to assess V2a interneuron distribution along the length of the spinal cord (Figure 2C). V2a interneuron soma number appeared to vary along the length of the spinal cord, with putative increases in the cervical and lumbar regions (Figure 2D). This proof-of-concept experiment demonstrates how PACT tissue clearing and 3D imaging can be applied to transgenic tdTomato fluorescent protein expression to investigate molecularly-defined subclasses of neurons in spinal cord neural circuits.

\section{PACT Clearing Enables 3D Imaging and Quantification of Acute Inflammation After SCl}

Inflammation after SCI has been predominantly characterized using tissue sections or by flow cytometry (Stirling and Yong, 2008; Beck et al., 2010). While important, these techniques fail to fully capture spatial information that may provide insight into the dynamics of various immune cell populations within the spinal cord parenchyma. To determine if tissue clearing and lightsheet imaging could provide unique assessment of the distribution of immune cells after SCI, we performed a contusive SCI and isolated spinal cords the following day. Despite the noticeable hemorrhaging, PACT tissue clearing successfully rendered the acutely injured spinal cord optically transparent (Figure 3A).

The compatibility of immune cell surface markers with tissue clearing has yet to be shown, however, we identified MRP8 as a granular protein predominantly expressed by neutrophils $\left(98.2 \pm 0.6 \%\right.$ of CD11b ${ }^{+} / \mathrm{MRP}^{+}$cells expressed the neutrophil specific marker, Ly6G; $n=5$ ) in the acutely injured spinal cord (Figure 3B). We found that MRP8 could be readily labeled by IF in cleared tissues (Figure 3C). Neutrophils are the first circulating immune cell population to invade the spinal cord in large numbers after injury and numerous $\mathrm{MRP}^{+}$cells were observed throughout the injured spinal cord at 1 day post-SCI, demonstrating significant accumulation of neutrophils. Co-labeling with NeuN demonstrated substantial loss of neurons at the lesion epicenter (Figure 3Di). The loss of NeuN coincided with a loss in MRP8 labeling near the lesion epicenter, which may be due to neutrophil degranulation (Figure 3Dii). In addition, we observed $\mathrm{MRP}^{+}$cells directly interacting with $\mathrm{NeuN}^{+}$neurons in single $\mathrm{z}$-stack plane images (Figure 3Diii, arrows). Using Imaris software, we quantified the number of infiltrated MRP8 ${ }^{+}$ cells (Figure 3E) and found a greater number of $\mathrm{MRP}^{+}$cells at the lateral edges of the SCI lesion (Figure 3F). These results demonstrate the potential for PACT clearing and 3D imaging to investigate the spatial dynamics of inflammation after SCI, which could provide critical insight for future therapeutic strategies such as immunomodulation.

\section{Uniform Labeling of White Matter After $\mathrm{SCl}$ in PACT Cleared Tissues}

One major limitation of utilizing whole tissues such as the brain and spinal cord is non-uniform labeling of abundant epitopes (or other endogenous biomolecules) due to outsidein labeling, which results in greater labeling on the perimeter of the tissue than in the center. A method to provide uniform labeling by controlling label interaction kinetics, called SWITCH (System-Wide control of Interaction Time and kinetics of CHemicals), has been recently described to enable uniform labeling of myelinated structures within the mouse brain (Murray et al., 2015). To determine if SWITCH could be used to visualize white matter in the mouse spinal cord, as well as damage to the white matter during SCI, we performed SWITCH mediated labeling of myelin with DiD. First, we assessed clearing of injured spinal cords at 42 days postSCI. Unlike the acutely injured spinal cord, the lesion site in the subacute phase of SCI could not be successfully cleared using PACT (Figure 4A, yellow arrows). The region within the spinal cord lesion could not be imaged due to excessive light scattering caused by the opaque lesion site tissue. However, the spared tissue region immediately surrounding the lesion did clear effectively and therefore could be readily imaged by lightsheet microscopy.

SWITCH-mediated labeling with DiD uniformly stained the white matter in the intact spinal cord (Figure $\mathbf{4 B}$ and Supplementary Movie 3). While substantial loss of white matter labeling was observed around the SCI lesion site, spared white matter tracts could still be observed around the SCI lesion (Figure 4C, white arrow; and Supplementary Movie 4). Furthermore, loss of white matter labeling in the dorsal column was also observed rostral to the SCI lesion, which could be associated with specific regions of demyelination or dieback of damaged axons (Figure 4Ci). These data demonstrate a straightforward method for labeling myelin in the intact and injured spinal cord after PACT clearing.

\section{PACT Facilitates 3D Visualization of Transplanted Neurons Within the Intact and Injured Spinal Cord}

Cell transplantation represents a promising solution to replace neuronal populations lost due to SCI (Fischer et al., 2020). However, assessment of neuronal survival and integration has been limited to histological tissue sections that capture only a small fraction of the transplanted cell population. To determine if PACT clearing and lightsheet imaging could better capture the transplant cell population, we transplanted hiPSC-derived V2a interneurons at four injection sites in the intact and injured spinal cord and assessed their survival and axon extension 2 weeks 
A

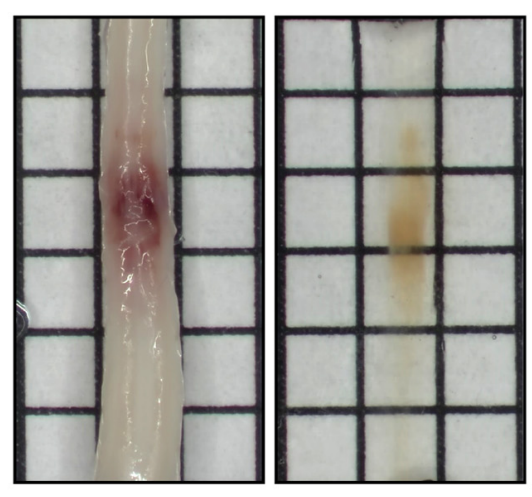

C

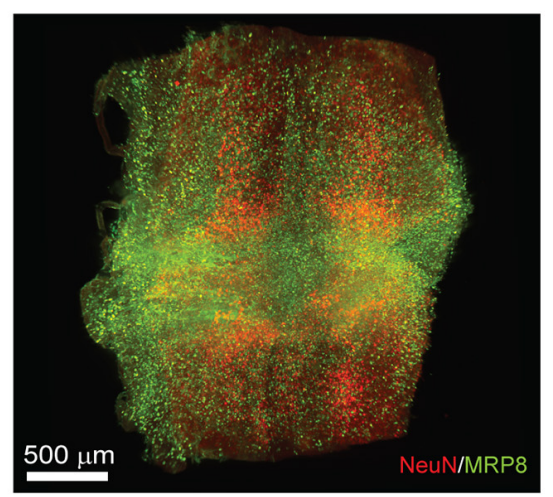

B

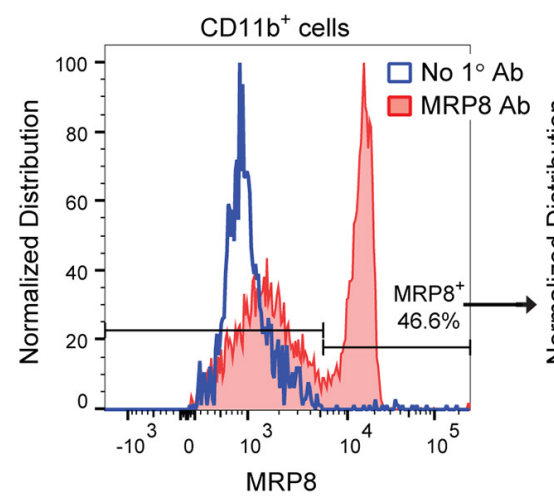

\section{D}

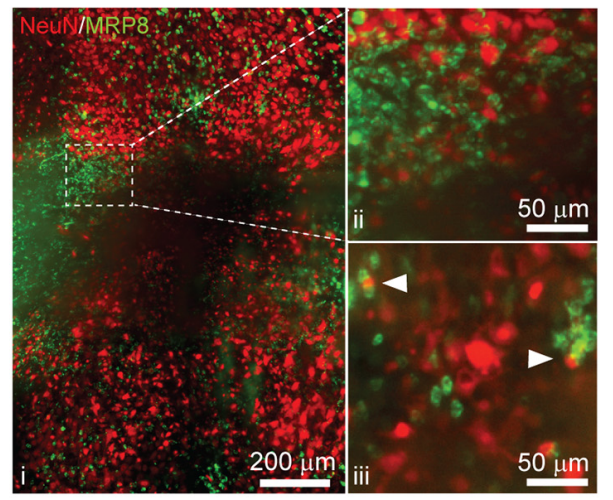

E

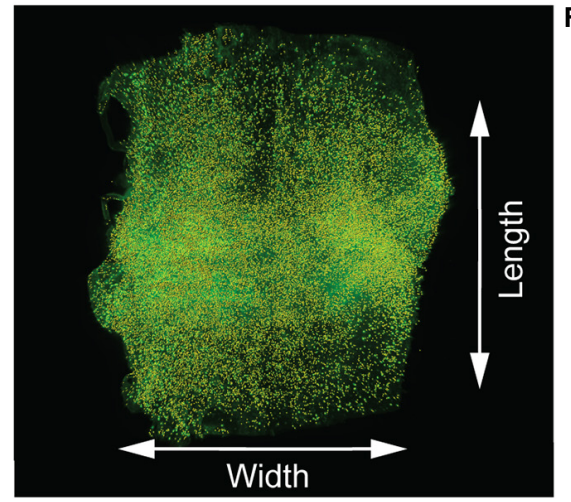

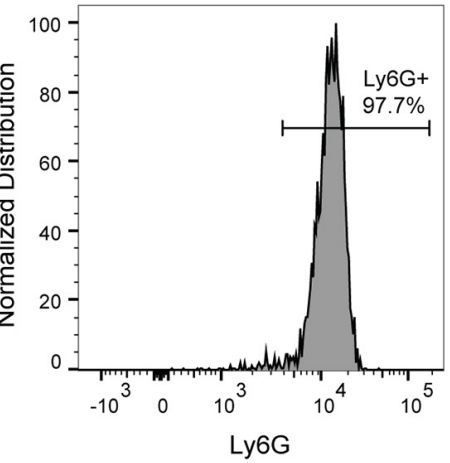

Ly6G

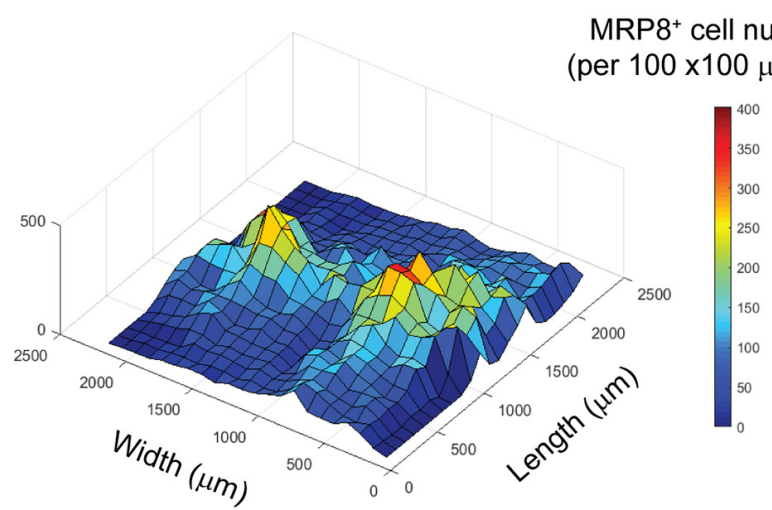

FIGURE 3 | 3D evaluation of inflammation in the acutely injured spinal cord using PACT clearing and lightsheet microscopy. (A) PACT clearing of the acutely injured spinal cord from a C57BI/6 mouse. (B) Representative flow cytometry histograms showing Ly6G expression in CD11b+/MRP8 ${ }^{+}$cells in the spinal cord at 1 day post-SCI $(n=1)$. (C) 3D projection of MRP8 and NeuN IF labeling in the cleared spinal cord at 1 day post-SCI. (D) Maximum intensity projection of MRP8 and NeuN IF labeling at the $\mathrm{SCl}$ site (i). Loss of $\mathrm{NeuN}^{+}$neurons and $\mathrm{MRP}^{+}$cells is observed toward the lesion epicenter (ii). Single z-plane images show MRP8 ${ }^{+}$cells interacting with $\mathrm{NeuN}^{+}$neurons (iii; arrows). (E) MRP8 ${ }^{+}$cell counting in Imaris (yellow dots). (F) Heat map of the spatial distribution of MRP8 ${ }^{+}$cells near the spinal cord lesion. SCl, spinal cord injury; IF, immunofluorescent.

later. In tissue sections, we were only able to observe cells labeled with a human specific Tau antibody (hTau) from one of the injection sites and long distance $\mathrm{hTau}^{+}$axon extension was difficult to assess due to axons entering and exiting the plane of the section (Figure 5A).

Conversely, clearing the whole spinal cord and performing lightsheet imaging allowed us to easily visualize all four injection sites in the intact spinal cord by hTau ${ }^{+}$IF labeling (Figures 5B,C). In addition, we could readily observe $\mathrm{hTau}^{+}$axon extension from the transplant site into the host spinal cord (Figure 5D, arrows; and Supplementary Movie 5). We also transplanted hiPSCderived V2a interneurons at 2 weeks post-SCI and collected spinal cord tissues for clearing 2 weeks later (Figure 5E). We observed variable $\mathrm{hTau}^{+}$cell survival at the four injection sites likely due to the less favorable environment of the injured spinal cord (Figure 5F and Supplementary Movie 6). From multiple transplant sites we observed $\mathrm{hTau}^{+}$axon extension into the spinal cord grey matter (Figure 5Fi), around the SCI 
A

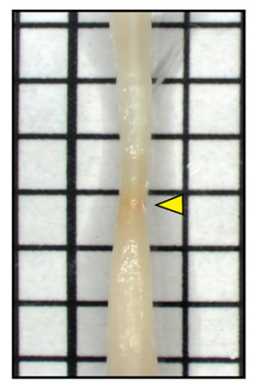

$\downarrow$ PACT clearing

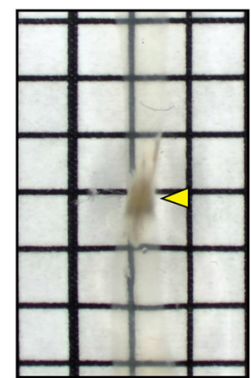

B
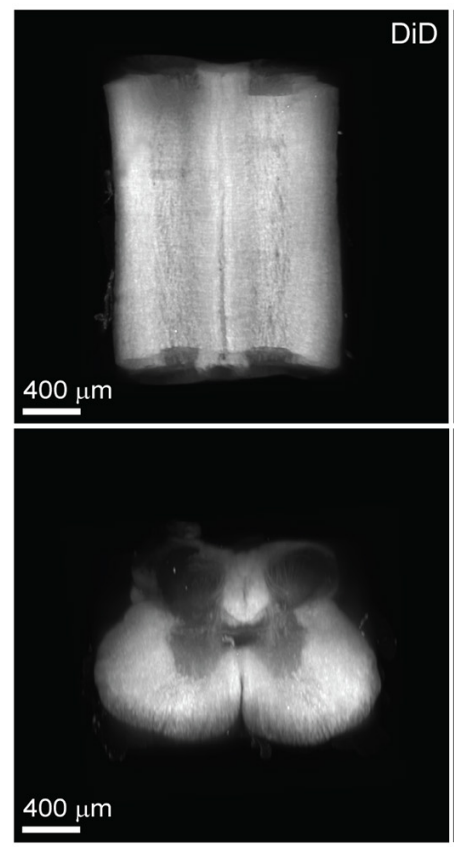

C
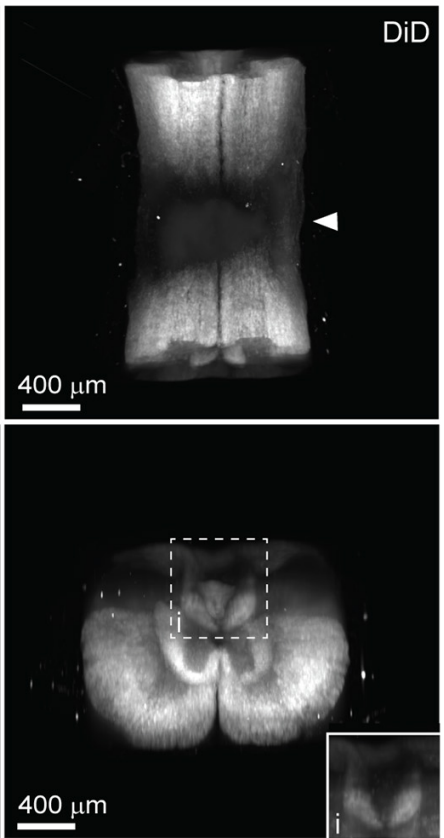

FIGURE 4 | Uniform white matter labeling following clearing of the long-term injured spinal cord. (A) PACT clearing of an injured spinal cord from a C57BI/6 mice at 42 days post-SCI. Poor clearing of the SCl lesion (yellow arrows) does not prevent 3D imaging of the cleared surrounding tissue. (B) 3D projection of SWITCH-mediated DiD labeling of the intact spinal cord from the dorsal and transverse views, respectively. (C) 3D projection of SWITCH-mediated DiD labeling of the injured spinal cord (at 42 days post-SCI) from the dorsal and transverse views, respectively. Spared white matter tracks can be visualized around the SCI lesion site (white arrow). (i) Magnified view of DiD labeling in the dorsal column. SCI, spinal cord injury.

lesion site (Figure 5Fii), and along the spinal cord white matter (Figure 5Fiii). These results show a new and promising approach for assessing transplant cell behavior in the mouse spinal cord.

\section{DISCUSSION}

This study describes a gentle and efficient method to clear the murine spinal cord through optimization of the PACT tissue clearing procedure. Hydrophilic and hydrogel-based approaches provide several advantages for tissue clearing including stability of endogenous and transgenic fluorescent protein signals, greater preservation of epitopes, increased tissue permeability for IF labeling, and compatibility with other aqueous-based histological staining procedures (Ueda et al., 2020). We modified several critical steps in the PACT clearing process which enabled robust clearing of the mouse spinal cord in as little as 6 days. While electrophoresis may further expedite clearing, we chose a passive approach to avoid the risk of tissue damage associated with electrophoretic tissue clearing, as well as the need for specialized equipment (Kim et al., 2015). The simple and reproducible approach described here is advantageous for enabling the broad applicability of spinal cord tissue clearing for many research laboratories.

Poor IF labeling is often observed in the thick CNS tissues used in tissue clearing studies due to limited diffusion and potential denaturation or purging of epitopes (Murray et al.,
2015). With the optimized PACT methodology, we achieved complete penetration of antibodies into the cleared spinal cord tissue in as little as 2 days. We identified robust labeling of cholinergic neurons (ChAT), neuronal soma (NeuN), neutrophils (MRP8), and transplanted human neurons (hTau). These data demonstrate the promising ability of the optimized PACT tissue clearing protocol and IF labeling for lightsheet imaging of whole spinal cords from mice. One major limitation we discovered in our study was the incomplete staining of highly abundant epitopes, which can deplete primary antibodies during outsidein staining (data not shown). Recent methodologies, such as SWITCH (Murray et al., 2015), have been developed to submaximally label epitopes or other endogenous biomolecules in a uniform manner throughout thick cleared tissues, which represents a critical first step in addressing the issue of nonuniform labeling.

Many of the studies utilizing tissue clearing and 3D imaging to study neural circuits in the spinal cord have relied on viral vectors encoding for fluorescent proteins such as eGFP and tdTomato to label specific neuronal populations ( $\mathrm{Ni}$ et al., 2014; Soderblom et al., 2015; Asboth et al., 2018; Wang et al., 2018; Hilton et al., 2019). One limitation to these strategies is the potential quenching of fluorescent protein signals by tissue clearing procedures, especially with hydrophobic protocols such as 3DISCO and BABB (Soderblom et al., 2015; Ueda et al., 2020). However, we demonstrated that PACT clearing is compatible with transgenic tdTomato fluorescence. 


\section{A}
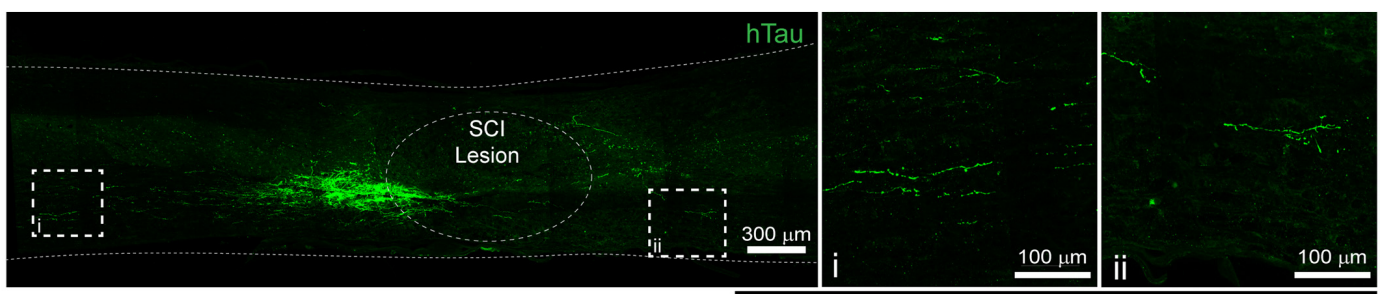

B

C

Transplanted hPSC-derived V2a interneurons

Tissue Clearing

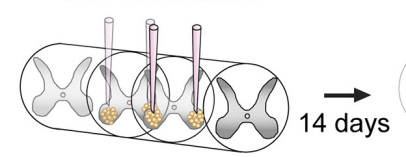

D
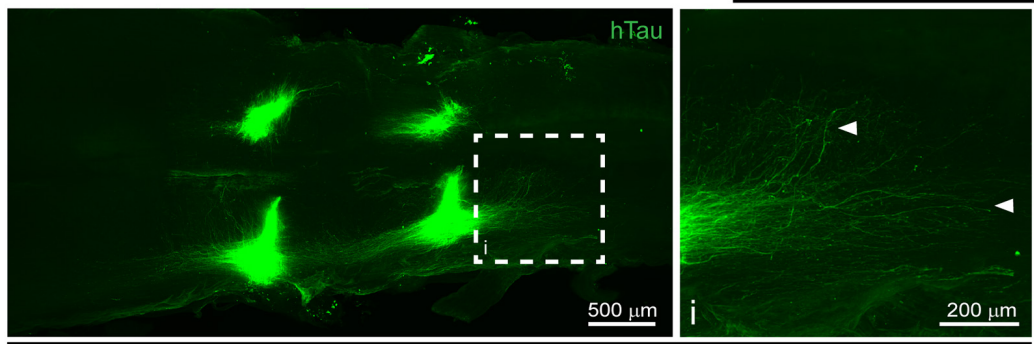

E

$\mathbf{F}$
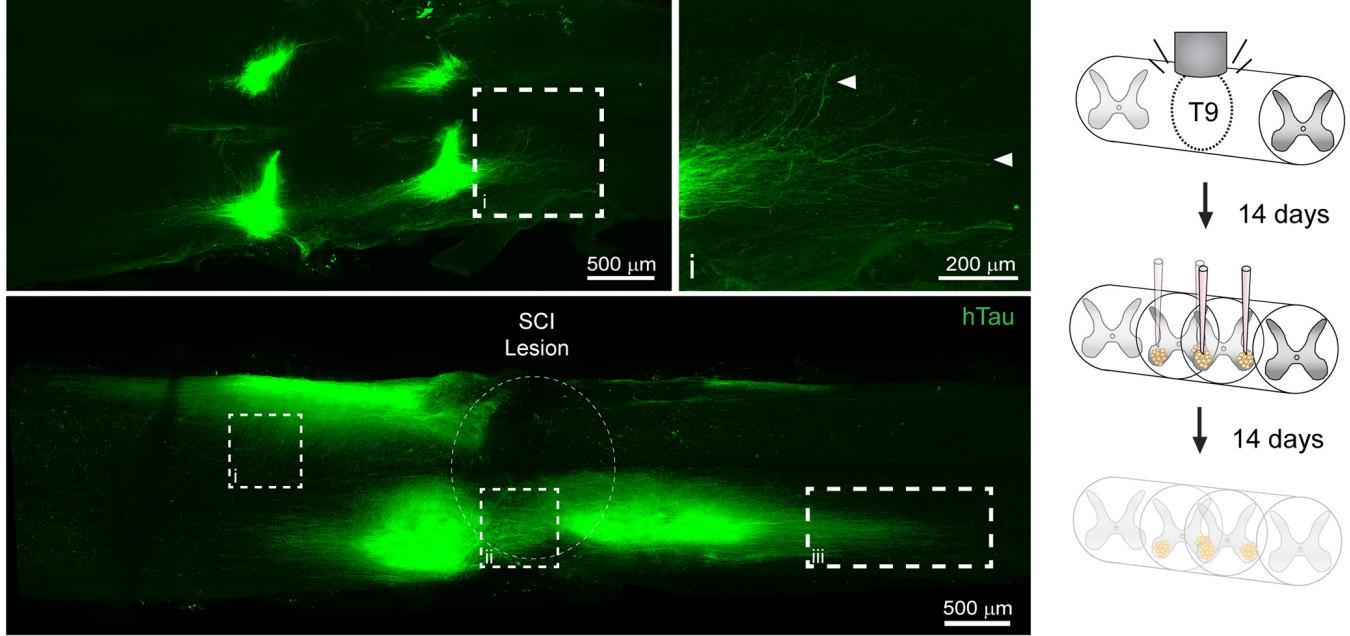

$1 \mathrm{~mm}$
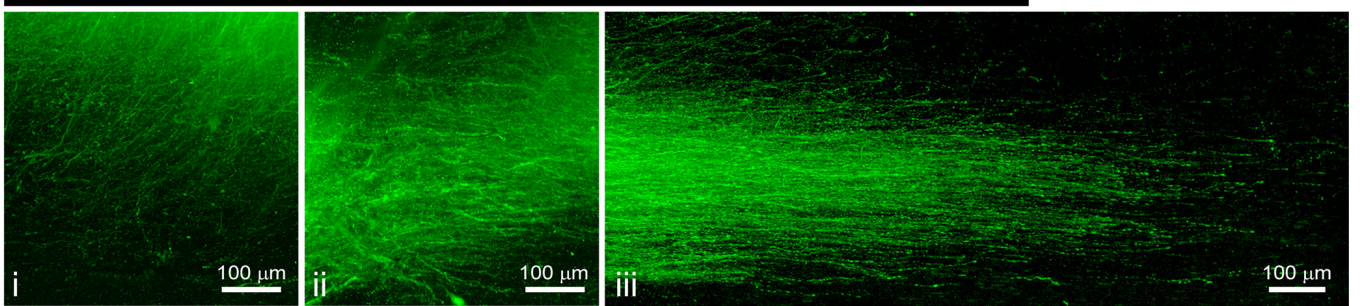

FIGURE 5 | Labeling and 3D imaging of transplanted hiPSC-derived V2a interneurons in the cleared intact and injured spinal cord of NSG mice. (A) hTau IF labeling in a sagittal section of the injured spinal cord at 14 days following transplantation. (i-ii) hTau ${ }^{+}$axons can only be visualized for a limited distance. (B) Schematic of hiPSC-derived V2a interneuron transplantation in the intact spinal cord and PACT clearing 14 days later. (C) 3D projection of hTau and NeuN IF labeling in the cleared intact spinal cord showing transplanted hiPSC-derived V2a interneurons. (D) Maximum intensity projection showing hTau ${ }^{+}$axon extension in the host spinal cord. (i) In cleared spinal cords, hTau+ axons can be visualized for long distances from the transplant site. (E) Schematic of SCl, hiPSC-derived V2a interneuron transplantation, and PACT clearing. (F) Maximum intensity projection of hTau IF labeling of hiPSC-derived V2a interneurons at 14 days following transplantation in the injured spinal cord. Axon extension is observed into the grey matter (i), around the SCl lesion site (ii), and distally along the white matter (iii). hiPSC, human induced pluripotent stem cell; hTau, human Tau; SCl, spinal cord injury.

The fluorescent intensity of tdTomato in cleared spinal cords from Chx10:tdTomato mice was sufficient to visualize soma morphology and axon extension from V2a interneurons even without signal amplification by IF labeling. This technique may be useful for mapping of spinal cord neural circuits and could be coupled with stochastic reporter mouse lines, such as Brainbow (Cai et al., 2013), to map dense neuronal populations across a broad fluorescent spectrum. PACT tissue clearing and 3D imaging may also enhance the analysis of neural circuit remodeling after SCI such as the previously 
described changes in spinal autonomic circuitry after high thoracic SCI (Ueno et al., 2016) and the recruitment of V2a interneurons after cervical SCI (Zholudeva et al., 2017). Although not all fluorescent proteins are compatible with the PACT clearing process (such as eGFP - data not shown), visualization of quenched transgenic fluorescence may be accomplished by IF labeling for antigenically distinct fluorescent proteins. Furthermore, common fluorophores are already being optimized for hydrogel-based tissue clearing applications (Scott et al., 2018). Combined with the optimized PACT clearing procedures presented, these advances can help elucidate the complex neural circuitry of the spinal cord.

Inflammation plays a critical role secondary injury following SCI, however, current techniques to assess immune cell populations, such as flow cytometry and histology, require dissociation or sectioning of the injured spinal cord tissue. At best, these techniques capture a limited view of the total spatial information. PACT clearing and IF labeling of MRP8 enabled easy visualization of neutrophils that have not undergone degranulation (released their granule contents) throughout the entire cleared spinal cord. $\mathrm{MRP}^{+}$neutrophils were found to be most abundant near the lateral edges, but not the rostral and caudal edges, of the lesion at 1 day post-SCI. This striking distribution of neutrophils with intact or residual granules in the acutely injured spinal cord would be difficult to determine using $2 \mathrm{D}$ tissue sections, thus demonstrating the utility of tissue clearing and 3D imaging. One major limitation we found in our study was poor IF labeling with traditional immune cell markers in cleared tissues (data not shown). The incompatibility of PACT clearing, as well as other clearing techniques, with the cell surface markers commonly used to specify immune cell subtypes might be due to removal of the majority of cell membranes during the delipidation phase of clearing. One method to overcome this limitation is the use of fluorescent reporter mice with immune cell type specific Cre lines to constitutively label cells with fluorescent proteins, such as tdTomato, that are compatible with PACT clearing as described earlier. Future studies are needed to better understand the role of neutrophils in the acutely injured spinal cord, however, the data in our study demonstrate the potential for tissue clearing and $3 \mathrm{D}$ imaging to better elucidate neutrophil functions in the spinal cord parenchyma.

White matter sparing is a common labor-intensive analysis of residual tissue after SCI that is typically performed using transverse tissue sections that can be extrapolated into a lowresolution $3 \mathrm{D}$ models. We demonstrate that loss of white matter following SCI could be observed in 3D images of cleared spinal cord tissue at 6 weeks post-injury. The sub-chronic SCI lesion site failed to fully clear using the PACT protocol, however, similar results have been previously shown using hydrogelbased clearing techniques (Asboth et al., 2018). This may be due in part to the inability of hydrophilic clearing techniques to clear extracellular matrix rich tissues, as previously shown (Azaripour et al., 2016). To visualize residual myelin, we utilized a lipid dye-based (DiD) strategy previously developed with the SWITCH procedures for uniform labeling (Murray et al., 2015). White matter labeled with $\mathrm{DiD}$ was easily visualized in both intact and injured spinal cord tissue and spared white matter tracts could be readily observed outside of the spinal cord lesion. Further development of this approach could increase the accuracy and reduce the time necessary for white matter sparing analyses.

Cell replacement therapies are a promising approach to repair the damaged neural circuitry of the spinal cord (Butts et al., 2017; Fischer et al., 2020), however, current histological procedures provide an incomplete interrogation of transplanted neurons in the host spinal cord. PACT clearing and 3D imaging enabled complete visualization of axon extension from transplanted hiPSC-derived V2a interneurons into the intact and injured spinal cord of mice. We identified transplanted human cells by IF labeling for a human specific form of the axonal marker Tau. As such, the described methods are limited to studying human neurons and more specifically their axons. However, fluorescent labeling of the transplanted cells could enable analysis of a wide variety of therapeutic cell populations from many different species. Our proof-of-concept studies demonstrate that tissue clearing and $3 \mathrm{D}$ imaging provide powerful insight into the assimilation of transplanted cell populations into the host spinal cord. The ability to interrogate the transplant architecture in cleared spinal cords may help improve future cell replacement strategies.

This report provides a detailed protocol for passive clearing of the mouse spinal cord that can be achieved without the need for specialized equipment. Fluorescent signals, either transgenic or from IF labeling, can be readily visualized in cleared tissues using confocal and lightsheet imaging. The new methodology has the potential to improve our understanding of spinal cord neural circuitry, mechanisms of secondary injury, and the discovery of effective therapeutic strategies. Future studies are needed to expand this technique to other species used for SCI research including rats and non-human primates.

\section{DATA AVAILABILITY STATEMENT}

The raw data supporting the conclusions of this article will be made available by the authors, without undue reservation.

\section{ETHICS STATEMENT}

The animal study was reviewed and approved by Institutional Animal Care and Use Committees at the University of California San Francisco, Texas A\&M University, and the Cincinnati Children's Hospital.

\section{AUTHOR CONTRIBUTIONS}

DM, NI, SS-E, SC, and TM contributed to conception and design of the study. RM, EM, JB, FJ, MP, SM, MK, AP, SR, and SC 
contributed to experimental design, data collection, and data analysis. DM wrote the first draft of the manuscript. FJ, MP, SM, MK, AP, and SR wrote sections of the manuscript. All authors contributed to manuscript revision, read, and approved the submitted version.

\section{FUNDING}

Funding was provided by the NIH NINDS F32NS096883 (DM), TIRR Foundation (DM), CIRM LA1-08015 (TM), the Roddenberry Foundation (TM), and Stuart Gordon (TM).

\section{ACKNOWLEDGMENTS}

Use of the Texas A\&M Microscopy and Imaging Center and the Gladstone Institutes Histology and Light Microscopy Core is acknowledged.

\section{REFERENCES}

Asboth, L., Friedli, L., Beauparlant, J., Martinez-Gonzalez, C., Anil, S., Rey, E., et al. (2018). Cortico-reticulo-spinal circuit reorganization enables functional recovery after severe spinal cord contusion. Nat. Neurosci. 21, 576-588. doi: 10.1038/s41593-018-0093-5

Azaripour, A., Lagerweij, T., Scharfbillig, C., Jadczak, A. E., Willershausen, B., and Van Noorden, C. J. (2016). A survey of clearing techniques for 3D imaging of tissues with special reference to connective tissue. Prog. Histochem. Cytochem. 51, 9-23. doi: 10.1016/j.proghi.2016.04.001

Beck, K. D., Nguyen, H. X., Galvan, M. D., Salazar, D. L., Woodruff, T. M., and Anderson, A. J. (2010). Quantitative analysis of cellular inflammation after traumatic spinal cord injury: evidence for a multiphasic inflammatory response in the acute to chronic environment. Brain 133, 433-447. doi: 10.1093/brain/ awp322

Butts, J. C., Iyer, N., White, N., Thompson, R., Sakiyama-Elbert, S., and McDevitt, T. C. (2019). V2a interneuron differentiation from mouse and human pluripotent stem cells. Nat. Protoc. 14, 3033-3058. doi: 10.1038/s41596-0190203-1

Butts, J. C., McCreedy, D. A., Martinez-Vargas, J. A., Mendoza-Camacho, F. N., Hookway, T. A., Gifford, C. A., et al. (2017). Differentiation of V2a interneurons from human pluripotent stem cells. Proc. Natl. Acad. Sci. U.S.A. 114, 4969-4974. doi: $10.1073 /$ pnas.1608254114

Cai, D., Cohen, K. B., Luo, T., Lichtman, J. W., and Sanes, J. R. (2013). Improved tools for the brainbow toolbox. Nat. Methods 10, 540-547. doi: 10.1038/nmeth. 2450

Chung, K., Wallace, J., Kim, S. Y., Kalyanasundaram, S., Andalman, A. S., Davidson, T. J., et al. (2013). Structural and molecular interrogation of intact biological systems. Nature 497, 332-337.

Erturk, A., Becker, K., Jahrling, N., Mauch, C. P., Hojer, C. D., Egen, J. G., et al. (2012). Three-dimensional imaging of solvent-cleared organs using 3DISCO. Nat. Protoc. 7, 1983-1995. doi: 10.1038/nprot.2012.119

Erturk, A., Mauch, C. P., Hellal, F., Forstner, F., Keck, T., Becker, K., et al. (2011). Three-dimensional imaging of the unsectioned adult spinal cord to assess axon regeneration and glial responses after injury. Nat. Med. 18, 166-171. doi: 10.1038/nm.2600

Fischer, I., Dulin, J. N., and Lane, M. A. (2020). Transplanting neural progenitor cells to restore connectivity after spinal cord injury. Nat. Rev. Neurosci. 21, 366-383. doi: 10.1038/s41583-020-0314-2

Griffin, J. M., and Bradke, F. (2020). Therapeutic repair for spinal cord injury: combinatory approaches to address a multifaceted problem. EMBO Mol. Med. 12:e11505.

\section{SUPPLEMENTARY MATERIAL}

The Supplementary Material for this article can be found online at: https://www.frontiersin.org/articles/10.3389/fncel. 2021.684792/full\#supplementary-material

Supplementary Movie 1 | 3D lightsheet image of ChAT (white) and NeuN (green) IF labeling in the PACT-cleared thoracic mouse spinal cord.

Supplementary Movie 2 | 3D lightsheet image of tdTomato fluorescence in V2a interneurons from $\mathrm{C} 1-\mathrm{L} 1$ in the cleared spinal cord from a Chx10:tdTomato mouse.

Supplementary Movie 3 | 3D lightsheet image of SWITCH-mediated DiD labeling in the intact spinal cord.

Supplementary Movie 4 | 3D lightsheet image of SWITCH-mediated DiD labeling in the injured spinal cord at 42 days post-SCl.

Supplementary Movie 5 | 3D lightsheet image of hTau (green) and NeuN (red) IF labeling in the intact spinal cord with transplanted hiPSC-derived V2a interneurons.

Supplementary Movie 6 | 3D lightsheet image of hTau IF labeling showing transplanted hiPSC-derived V2a interneurons in the injured spinal cord.

Hilton, B. J., Blanquie, O., Tedeschi, A., and Bradke, F. (2019). High-resolution 3D imaging and analysis of axon regeneration in unsectioned spinal cord with or without tissue clearing. Nat. Protoc. 14, 1235-1260. doi: 10.1038/s41596-0190140-Z

Kim, S. Y., Cho, J. H., Murray, E., Bakh, N., Choi, H., Ohn, K., et al. (2015). Stochastic electrotransport selectively enhances the transport of highly electromobile molecules. Proc. Natl. Acad. Sci. U.S.A. 112, E6274-E6283.

Kwon, B. K., Okon, E., Hillyer, J., Mann, C., Baptiste, D., Weaver, L. C., et al. (2011a). A systematic review of non-invasive pharmacologic neuroprotective treatments for acute spinal cord injury. J. Neurotrauma 28, 1545-1588. doi: 10.1089/neu.2009.1149

Kwon, B. K., Okon, E. B., Plunet, W., Baptiste, D., Fouad, K., Hillyer, J., et al. (2011b). A systematic review of directly applied biologic therapies for acute spinal cord injury. J. Neurotrauma 28, 1589-1610. doi: 10.1089/neu.2009. 1150

McCreedy, D. A., Lee, S., Sontag, C. J., Weinstein, P., Olivas, A. D., Martinez, A. F., et al. (2018). Early targeting of L-selectin on leukocytes promotes recovery after spinal cord injury, implicating novel mechanisms of pathogenesis. eNeuro 5 , 0101-0118.

Murray, E., Cho, J. H., Goodwin, D., Ku, T., Swaney, J., Kim, S. Y., et al. (2015). Simple, scalable proteomic imaging for high-dimensional profiling of intact systems. Cell 163, 1500-1514. doi: 10.1016/j.cell.2015.11.025

Ni, Y., Nawabi, H., Liu, X., Yang, L., Miyamichi, K., Tedeschi, A., et al. (2014). Characterization of long descending premotor propriospinal neurons in the spinal cord. J. Neurosci. 34, 9404-9417. doi: 10.1523/jneurosci.177114.2014

Pawlowski, S. A., Gaillard, S., Ghorayeb, I., Ribeiro-da-Silva, A., Schlichter, R., and Cordero-Erausquin, M. (2013). A novel population of cholinergic neurons in the macaque spinal dorsal horn of potential clinical relevance for pain therapy. J. Neurosci. 33, 3727-3737. doi: 10.1523/jneurosci.395412.2013

Pocratsky, A. M., Burke, D. A., Morehouse, J. R., Beare, J. E., Riegler, A. S., Tsoulfas, P., et al. (2017). Reversible silencing of lumbar spinal interneurons unmasks a task-specific network for securing hindlimb alternation. Nat. Commun. 8:1963.

Renier, N., Wu, Z., Simon, D. J., Yang, J., Ariel, P., and Tessier-Lavigne, M. (2014). iDISCO: a simple, rapid method to immunolabel large tissue samples for volume imaging. Cell 159, 896-910. doi: 10.1016/j.cell.2014. 10.010

Richardson, D. S., and Lichtman, J. W. (2015). Clarifying tissue clearing. Cell 162, 246-257. doi: 10.1016/j.cell.2015.06.067 
Scott, D. J., Gunn, N. J., Yong, K. J., Wimmer, V. C., Veldhuis, N. A., Challis, L. M., et al. (2018). A novel ultra-stable, monomeric green fluorescent protein for direct volumetric imaging of whole organs using clarity. Sci. Rep. 8:667.

Soderblom, C., Lee, D. H., Dawood, A., Carballosa, M., Jimena Santamaria, A., Benavides, F. D., et al. (2015). 3D imaging of axons in transparent spinal cords from rodents and nonhuman primates. eNeuro 2, 0001-0015.

Steward, O., Zheng, B., and Tessier-Lavigne, M. (2003). False resurrections: distinguishing regenerated from spared axons in the injured central nervous system. J. Comp. Neurol. 459, 1-8. doi: 10.1002/cne.10593

Stirling, D. P., and Yong, V. W. (2008). Dynamics of the inflammatory response after murine spinal cord injury revealed by flow cytometry. J. Neurosci. Res. 86, 1944-1958. doi: 10.1002/jnr.21659

Susaki, E. A., and Ueda, H. R. (2016). Whole-body and whole-organ clearing and imaging techniques with single-cell resolution: toward organism-level systems biology in mammals. Cell Chem. Biol. 23, 137-157. doi: 10.1016/j.chembiol. 2015.11.009

Tainaka, K., Murakami, T. C., Susaki, E. A., Shimizu, C., Saito, R., Takahashi, K., et al. (2018). Chemical landscape for tissue clearing based on hydrophilic reagents. Cell Rep. 24, 2196-2210.e9.

Tetzlaff, W., Okon, E. B., Karimi-Abdolrezaee, S., Hill, C. E., Sparling, J. S., Plemel, J. R., et al. (2011). A systematic review of cellular transplantation therapies for spinal cord injury. J. Neurotrauma 28, 1611-1682.

Tomer, R., Ye, L., Hsueh, B., and Deisseroth, K. (2014). Advanced clarity for rapid and high-resolution imaging of intact tissues. Nat. Protoc. 9, 1682-1697. doi: $10.1038 /$ nprot.2014.123

Treweek, J. B., Chan, K. Y., Flytzanis, N. C., Yang, B., Deverman, B. E., Greenbaum, A., et al. (2015). Whole-body tissue stabilization and selective extractions via tissue-hydrogel hybrids for high-resolution intact circuit mapping and phenotyping. Nat. Protoc. 10, 1860-1896. doi: 10.1038/nprot.20 15.122

Ueda, H. R., Erturk, A., Chung, K., Gradinaru, V., Chedotal, A., Tomancak, P., et al. (2020). Tissue clearing and its applications in neuroscience. Nat. Rev. Neurosci. 21, 61-79. doi: 10.1038/s41583-019-0250-1

Ueno, M., Ueno-Nakamura, Y., Niehaus, J., Popovich, P. G., and Yoshida, Y. (2016). Silencing spinal interneurons inhibits immune suppressive autonomic reflexes caused by spinal cord injury. Nat. Neurosci. 19, 784-787. doi: 10.1038/ nn. 4289
Wang, Z., Maunze, B., Wang, Y., Tsoulfas, P., and Blackmore, M. G. (2018). Global connectivity and function of descending spinal input revealed by $3 \mathrm{~d}$ microscopy and retrograde transduction. J. Neurosci. 38, 10566-10581. doi: 10.1523/jneurosci.1196-18.2018

Woo, J., Lee, M., Seo, J. M., Park, H. S., and Cho, Y. E. (2016). Optimization of the optical transparency of rodent tissues by modified PACT-based passive clearing. Exp. Mol. Med. 48:e274. doi: 10.1038/emm.2016.105

Yang, B., Treweek, J. B., Kulkarni, R. P., Deverman, B. E., Chen, C. K., Lubeck, E., et al. (2014). Single-cell phenotyping within transparent intact tissue through whole-body clearing. Cell 158, 945-958. doi: 10.1016/j.cell.2014. 07.017

Zhang, M. D., Tortoriello, G., Hsueh, B., Tomer, R., Ye, L., Mitsios, N., et al. (2014). Neuronal calcium-binding proteins $1 / 2$ localize to dorsal root ganglia and excitatory spinal neurons and are regulated by nerve injury. Proc. Natl. Acad. Sci. U.S.A. 111, E1149-E1158.

Zholudeva, L. V., Karliner, J. S., Dougherty, K. J., and Lane, M. A. (2017). Anatomical recruitment of spinal V2a interneurons into phrenic motor circuitry after high cervical spinal cord injury. J. Neurotrauma 34, 3058-3065. doi: $10.1089 /$ neu.2017.5045

Conflict of Interest: The authors declare that the research was conducted in the absence of any commercial or financial relationships that could be construed as a potential conflict of interest.

Publisher's Note: All claims expressed in this article are solely those of the authors and do not necessarily represent those of their affiliated organizations, or those of the publisher, the editors and the reviewers. Any product that may be evaluated in this article, or claim that may be made by its manufacturer, is not guaranteed or endorsed by the publisher.

Copyright (c) 2021 McCreedy, Jalufka, Platt, Min, Kirchhoff, Pritchard, Reid, Manlapaz, Mihaly, Butts, Iyer, Sakiyama-Elbert, Crone and McDevitt. This is an open-access article distributed under the terms of the Creative Commons Attribution License (CC BY). The use, distribution or reproduction in other forums is permitted, provided the original author(s) and the copyright owner(s) are credited and that the original publication in this journal is cited, in accordance with accepted academic practice. No use, distribution or reproduction is permitted which does not comply with these terms. 